\title{
Mitochondrial targeted strategies and their application for cancer and other diseases treatment
}

\author{
Qiuyi $\mathrm{Li}^{1} \cdot$ Yuan Huang ${ }^{1}$
}

Received: 11 February 2020 / Accepted: 1 April 2020 / Published online: 6 April 2020

(c) The Author(s) 2020, corrected publication 2020

\begin{abstract}
Background Known as the main site of ATP production and intrinsic apoptosis regulator, mitochondria play vital roles in physiological functions and pathological progression. Evidences have shown that mitochondrial dysfunction correlated with a variety of diseases, especially with cancer. Mitochondria are emerged as an attractive target for diseases treatment.

Area covered This review introduces efficient mitochondrial targeting strategies, and summarizes application of multiple drug delivery systems targeted to mitochondria for antitumor treatment, including anti-drug resistance, anti-metastasis and immunotherapy. Furthermore, we discuss the application and perspectives of mitochondrial targeting in treatment of other mitochondrial-related diseases.

Expert opinion A number of chemotherapeutics exert their efficacy in specific sub-organelles. Targeting drugs to one certain organelle would exhibit their maximum therapeutic effects. The mitochondria in tumor cells are closely related to the development of tumor. Also, the main cause of clinical failure in antitumor treatment, including multidrug resistance (MDR) and metastasis, are associated with mitochondrial dysfunction. In addition, mitochondria disorders also lead to some other diseases. Therefore, constructing mitochondrial targeted drug delivery systems to regulate mitochondrial functions is necessarily desired.
\end{abstract}

Keywords Mitochondria $\cdot$ Targeted strategies $\cdot$ Drug delivery systems $\cdot$ Antitumor $\cdot$ Mitochondrial-related diseases

\section{Introduction}

Mitochondria are the main site of ATP production, known as the "power house" of eukaryotic cells. In addition to the vital physiological functions, mitochondria also participate in pathological progression (Lu et al. 2016; Yamada and Harashima 2008). Many studies have demonstrated that mitochondrial dysfunction was closely related to the development of multiple diseases, including diabetes (Lowell and Shulman 2005; Szendroedi et al. 2011), nonalcoholic fatty liver disease (NAFLD) (Sanyal et al. 2001; Wei et al. 2008), cardiovascular and neurodegenerative diseases (Chan 2006), kidney injury (Hallan and Sharma 2016; Hall and Schuh 2016) and cancer (Wallace 2012; Fulda et al.

Yuan Huang

huangyuan0@163.com

1 Key Laboratory of Drug Targeting and Drug Delivery System (Ministry of Education), West China School of Pharmacy, Sichuan University, No. 17, Block 3, South Renmin Road, Chengdu 610041, People's Republic of China
2010; Battogtokh et al. 2018). Therefore, mitochondria are emerged as an attractive target for diseases treatment.

Mitochondria with a double-membrane structure are composed of outer membrane (OMM), interspace membrane (ISM), inner mitochondrial membrane (IMM), and matrix (Lu et al. 2016). The matrix contains DNA (mtDNA), which encodes important proteins for oxidative phosphorylation. mtDNA lacks introns and self-repair ability, making it more vulnerable to mutation and damage than nuclear DNA (nDNA) (Yamada and Harashima 2008). mtDNA mutation can affect respiratory chain and increase reactive oxygen species (ROS) generation, whereas overproduced ROS in turn destroy mtDNA as well as cellular lipids, proteins and nDNA. Long-time exposure to ROS can induce cell death. But once the mutated cells survive, they may trigger tumorigenesis ( $\mathrm{Lu}$ et al. 2016). Evidences showed that numerous mutations of mtDNA led to a variety of malignancies, including breast cancer, colon cancer and prostate cancer (Wallace 2012; Fulda et al. 2010).

Mitochondria are the center regulator of intrinsic apoptosis pathway, by regulating the balance of pro-apoptosis and 
anti-apoptosis to induce programmed cell death. Generally the OMM permeabilization occurs under stimuli, leading to cytochrome $\mathrm{C}$ release from ISM to cytosol and downstream cascade activation, consequently induce apoptosis (Lu et al. 2016). Escaping from cell death is a hallmark of tumor cells, which is associated with apoptosis blockade. Thus, drugs developed to promote apoptosis pathway is an effective strategy for anticancer treatment (Fulda et al. 2010).

Due to the crucial role of mitochondria in tumor generation and progression, mitochondrial targeted antitumor therapy is necessarily desired. However, mitochondrial membranes exert very low permeability, of which the OMM and IMM only permit molecules less than $5000 \mathrm{Da}$ and $1500 \mathrm{Da}$ to pass through, respectively (Kroemer et al. 2007; Yamada and Harashima 2008). Herein, delivering drugs to mitochondria is rather tough. In this review, we introduce efficient mitochondrial targeting strategies, and summarize application of multiple drug delivery systems targeted to mitochondria for antitumor treatment, including anti-drug resistance, anti-metastasis and immunotherapy. Furthermore, we discuss the application and perspectives of mitochondrial targeting in treatment of other mitochondrial-related diseases.

\section{Mitochondrial targeted strategies}

There are several ways to classify mitochondrial targeted strategies, one is to classify by the molecular weight and type of targeted substances, including small molecules, peptides and vehicles. Others such as targeting mechanisms (membrane potential-mediated, membrane import machinery-mediated and active targeting) and types of delivered molecules (small molecule drugs, proteins and gene) are also included (Yamada and Harashima 2008; Fulda et al. 2010). Here, we discuss commonly mitochondrial targeted strategies according to the first category (Table 1).

\section{Small molecules for mitochondrial targeted strategy}

In the past, researches have reported that some small molecules had high localization in mitochondria. These molecules have special properties (e.g., lipophilicity, positive potential) and could specifically interact with mitochondria membrane or have high affinity with particular receptors or substances secreted by the mitochondria. Therefore, they were used for the targeted delivery of drugs to mitochondria.

\section{Positively charged lipophilic small molecules}

To realize successful mitochondrial localization, molecules need to penetrate both plasma membrane and mitochondrial membranes. The plasma membrane, usually displays $\mathrm{a}-30$ to $-60 \mathrm{mV}$ potential, drives 5- to 10-fold higher accumulation of cations in cytoplasm via electrostatic interaction compared with extracellular space. Mitochondria, known to possess more negative membrane potential ( -150 to $-180 \mathrm{mV}$ ), further allowed them to accumulate 100 to 500 -fold higher in mitochondrial matrix (Smith et al. 2003). What's more, as mitochondria are double-membrane organelles, the dynamics of the equilibration uptake process remarkably depend on the hydrophobicity of cations (Zielonka et al. 2017). The more lipophilic the cation, the easier it is to cross phospholipid bilayers to locate in mitochondrial matrix. Herein, molecules with both strong positive charge and lipophilicity are more likely to distribute in mitochondrial matrix.

Delocalized lipophilic cations (DLCs) are lipophilic cations with a delocalized positive charge, which can efficiently pass through lipophilic mitochondrial membranes and selectively accumulate in mitochondrial matrix in response to the strongly negative charge of IMM (Lu et al. 2016; Modica-Napolitano and Aprille 2001). One of typical DLCs, tetraphenylphosphonium (TPP), was proved to penetrate through phospholipid bilayers membrane driven by the membrane potential by means of thermodynamic analysis and activation energy determination (Flewelling and Hubbell 1986; Ono et al. 1994). Rugolo et al. utilized TPP to determine both isolated and intracellular mitochondrial membrane potential due to the abundant amount of TPP taken up by mitochondria (Rugolo and Lenaz 1987). The uptake of TPP in mitochondria is a multiple process. First, it binds to the negative phosphate of the cytosolic face of IMM; then it transfers to the matrix side of IMM and finally detached from the membrane to enter into matrix (Smith et al. 2003; Zielonka et al. 2017). TPP has been widely used for mitochondrial targeted drug delivery in the past thirty years. Antioxidants such as vitamin E and lipoic acid conjugated to TPP showed tens to hundreds times higher mitochondrial accumulation (Smith et al. 1999; Brown et al. 2007). Similarly, DNA-damage anticancer agents like doxorubicin (DOX) and chlorambucil were conjugated to TPP to realize enhanced cellular uptake and selective mitochondrial distribution for anticancer treatment (Han et al. 2014; Millard et al. 2013). In addition to small molecular drugs, nanocarriers with TPP decoration also exhibited greater mitochondrial localization, of which TPP modified liposome and TPP-poly $(\varepsilon-$ caprolactone) nanoparticle showed 3.18-fold and 3.8-fold higher mitochondrial accumulation than those non-modified nanosystems, respectively (Zhou et al. 2013; Cho et al. 2015). What's more, ${ }^{64} \mathrm{Cu}$-labelled TPP were found to be able to provide tumor images and monitor mitochondrial bioenergetics. Due to its low lipophilicity $(\log P=-2.03$ to -2.67 ) and high positive charge, ${ }^{64} \mathrm{Cu}$-labelled TPP exhibited excellent tumor and mitochondrial selectivity in vivo, respectively (Millard et al. 2013). Other DLCs like 
Table 1 Strategies of mitochondrial targeting

\begin{tabular}{|c|c|c|c|c|}
\hline Targeting group & Drug or vehicle & Cell line and model & Main efficacy & Refs \\
\hline \multirow[t]{6}{*}{ TPP } & Vitamin E & Osteosarcoma 143B cells & $\begin{array}{l}\text { Enhanced mitochondrial } \\
\text { IMM accumulation; pro- } \\
\text { tecting mitochondria from } \\
\text { oxidative damage }\end{array}$ & Smith et al. (1999) \\
\hline & Lipoic acid & $\begin{array}{l}\text { Jurkat cells, rat liver mito- } \\
\text { chondria }\end{array}$ & $\begin{array}{l}\text { Several-hundred fold higher } \\
\text { accumulations than free } \\
\text { lipoic acid }\end{array}$ & Brown et al. (2007) \\
\hline & Chlorambucil & $\begin{array}{l}\text { MDA-MB-231, MDA- } \\
\text { MB-435, MIA PaCa-2 } \\
\text { xenograft mice }\end{array}$ & $\begin{array}{l}\text { Increased mitochondrial dis- } \\
\text { tribution and tumor growth } \\
\text { inhibition }\end{array}$ & Millard et al. (2013) \\
\hline & Doxorubicin & $\begin{array}{l}\text { MDA-MB-435/WT, MDA- } \\
\text { MB-435/DOX }\end{array}$ & $\begin{array}{l}\text { Enhanced cellular uptake } \\
\text { and mitochondrial distribu- } \\
\text { tion, MDR reversal }\end{array}$ & Han et al. (2014) \\
\hline & Liposome & $\mathrm{A} 549, \mathrm{~A} 549 / \mathrm{cDDP}$ & $\begin{array}{l}\text { 3.18-fold higher mitochon- } \\
\text { drial accumulation and } \\
\text { MDR reversal }\end{array}$ & Zhou et al. (2013) \\
\hline & $\begin{array}{l}\text { Poly( }(\varepsilon \text {-caprolactone }) \text { nano- } \\
\text { particle }\end{array}$ & HeLa, HepG2 & $\begin{array}{l}\text { 3.8-fold higher mitochon- } \\
\text { drial accumulation and } \\
\text { superior tumor killing } \\
\text { activity }\end{array}$ & Cho et al. (2015) \\
\hline \multirow[t]{4}{*}{ Guanidine } & Sorbitol & $\mathrm{HeLa}$ & $\begin{array}{l}\text { Unique intracellular selectiv- } \\
\text { ity toward mitochondria }\end{array}$ & Maiti et al. (2007) \\
\hline & Porphyrin & HEp2 & $\begin{array}{l}\text { Promoted mitochondrial dis- } \\
\text { tribution and phototoxicity }\end{array}$ & Sibrian-Vazquez et al. (2008) \\
\hline & Cyclometalated iridium (III) & $\begin{array}{l}\text { HeLa, MCF-7, HepG2, } \\
\text { CNE-2, A549, A549R and } \\
\text { LO2 }\end{array}$ & $\begin{array}{l}\text { Excellent mitochondrial } \\
\text { colocalization and apopto- } \\
\text { sis induction }\end{array}$ & Song et al. (2017) \\
\hline & HPMA copolymer & $\mathrm{B} 16 \mathrm{~F} 10$ & $\begin{array}{l}\text { 24.5-fold higher mitochon- } \\
\text { drial accumulation }\end{array}$ & Wang et al. (2017) \\
\hline \multirow[t]{2}{*}{ Glycyrrhetinic acid } & Graphene Oxide/DOX & $\begin{array}{l}\text { HepG2, LO2, and } \mathrm{H} 9 \mathrm{c} 2 \\
\text { HepG2 xenograft mice }\end{array}$ & $\begin{array}{l}\text { Specific distribution in mito- } \\
\text { chondria and apoptosis } \\
\text { activation }\end{array}$ & Zhang et al. (2018) \\
\hline & GNP & HepG2, HepG2/ADR & $\begin{array}{l}\text { 4-fold higher cell internaliza- } \\
\text { tion and } 8.8 \text {-fold higher } \\
\text { mitochondrial accumula- } \\
\text { tion }\end{array}$ & Liu et al. (2019) \\
\hline \multirow[t]{2}{*}{ MTS } & Exonuclease III -TAT & MDA-MB-231 & $\begin{array}{l}\text { Enhanced cellular uptake } \\
\text { and mitochondrial localiza- } \\
\text { tion }\end{array}$ & $\begin{array}{l}\text { Del Gaizo and Mark Payne } \\
\text { (2003) }\end{array}$ \\
\hline & sC18-chlorambucil & HeLa & $\begin{array}{l}\text { Enhanced mitochondrial } \\
\text { accumulation and cyto- } \\
\text { toxicity }\end{array}$ & Klimpel and Neundorf (2018) \\
\hline \multirow[t]{3}{*}{ MPP } & Doxorubicin & $\begin{array}{l}\text { HeLa, A2780 and A2780/ } \\
\text { ADR }\end{array}$ & $\begin{array}{l}\text { Promoted cellular uptake and } \\
\text { mitochondrial distribution, } \\
\text { MDR reversal }\end{array}$ & Chamberlain et al. (2013) \\
\hline & Cisplatin & A2780, A2780CP70 & $\begin{array}{l}\text { Promoted cellular uptake and } \\
\text { mitochondrial distribution, } \\
\text { MDR reversal }\end{array}$ & Wisnovsky et al. (2013) \\
\hline & HPMA copolymer & MCF-7, MCF-7/ADR & $\begin{array}{l}\text { 11.6-fold higher mitochon- } \\
\text { drial accumulation and } \\
\text { MDR reversal }\end{array}$ & Zhou et al. (2019) \\
\hline SS peptides & & $\begin{array}{l}\text { Caco-2, N2A cells, rat liver } \\
\text { mitochondria }\end{array}$ & $\begin{array}{l}\text { Selective distribution in } \\
\text { IMM, scavenging per- } \\
\text { oxynitrite and hydrogen } \\
\text { peroxide, inhibiting lipid } \\
\text { peroxidation }\end{array}$ & Zhao et al. (2004) \\
\hline
\end{tabular}


Table 1 (continued)

\begin{tabular}{lllll}
\hline Targeting group & Drug or vehicle & Cell line and model & Main efficacy & Refs \\
\hline MITO-Porter & Liposome & HeLa, C57BL/6 mice & $\begin{array}{c}\text { Targeted deliver cargos to } \\
\text { mitochondrial IMS by } \\
\text { means of membrane fusion }\end{array}$ & $\begin{array}{c}\text { Yamada et al. (2015) and Abe } \\
\text { et al. (2016) }\end{array}$ \\
MSN & MSN & HeLa & $\begin{array}{c}\text { Approximately 3-fold higher } \\
\text { mitochondrial localization et al. (2017) } \\
\text { than negatively charged } \\
\end{array}$ \\
& & MSN & \\
\hline
\end{tabular}

dequalinium (DQA) and rhodamine 123 have also been used for mitochondrial targeted drug delivery (Battogtokh et al. 2018; Modica-Napolitano and Aprille 2001).

Guanidine, one of the strongest organic bases, was originally noted as an important component of cell penetrating peptide TAT. The D-arginine oligomer (R9) with repeated guanidine showed 100 -fold greater cellular uptake than TAT, implying the efficient plasma membrane penetrating capability of guanidine (Wender et al. 2000). Owing to its hydrogen bond donor and receptor ability, guanidine was easily modified onto drugs or biologic molecules and widely used for antimicrobial and antimalarial drug design (Song et al. 2017). Moreover, its strong positive charge also contributed to specific interaction with negative mitochondrial membrane, revealing the high potential for subcellular targeted drug delivery. Maiti et al. demonstrated that sorbitol carrying eight guanidine base residues could realize unique intracellular organelle selectivity towards mitochondria (Maiti et al. 2007). Guanidine conjugated to porphyrins or cyclometalated iridium (III) also showed increased cell internalization and excellent mitochondrial colocalization (Sibrian-Vazquez et al. 2008; Song et al. 2017). Besides, our group attached guanidine to N-(2-hydroxypropyl) methacrylamide (HPMA) copolymer and this positively charged copolymer displayed 4.27 -fold higher cellular uptake and 24.5-fold higher mitochondrial accumulation than non-decorated one, revealing the efficient mitochondrial targeted capability of guanidine (Wang et al. 2017).

Though many advantages of these positive and lipophilic small molecules, there are also some shortcomings for their therapeutic application. The positive chargedependent cellular uptake is lack of specificity, which may also promote the cell internalization of normal tissues or cells, resulting in unexpected side effects (Saar et al. 2005; Jones et al. 2005). Besides, strongly positive molecules or nanosystems are easily to be cleared by reticuloendothelial system (RES), leading to poor blood circulation and insufficient therapeutic efficacy (Souris et al. 2010; Xiao et al. 2011). Therefore, how to solve the above problems is crucial for application of these small molecules for mitochondrial targeted drug delivery.

\section{Small-molecule ligand}

Some small-molecule ligands were also found to have high affinity with particular receptor or substances secreted by the mitochondria and thus used for mitochondrial drug delivery. Glycyrrhetinic acid (GA), an active ingredient extracted from the root of traditional herb licorice, with anti-inflammatory, antioxidant and antiviral effects, has been used for antitussive and peptic ulcer since 1940s (Shibata 2000). GA is able to induce apoptosis in cancer cells, perhaps associated with mitochondrial damage and intrinsic apoptotic activation activity (Sharma et al. 2012; Lee et al. 2008; Yang et al. 2012a). Moreover, it has been proven that GA could bind with protein kinase $\mathrm{C} \alpha$, which is highly expressed on the surface of hepatocellular carcinoma rather than normal hepatocytes, and were usually utilized as an active-targeting ligand (Chen et al. 2015; Zhang et al. 2012). Recently, Zhang et al. observed that GA functionalized graphene oxideDOX had a specific distribution in mitochondria instead of nucleus, implying that it might possess mitochondrial targeting capacity (Zhang et al. 2018). The underlying mechanism was not very clear, possibly associated with the interaction between GA and mitochondrial respiratory chain complex (Fiore et al. 2004). Since GA could generate hydrogen peroxide which led to the opening of mitochondrial permeability transition pore (MPTP) when $\mathrm{Ca}^{2+}$ was also present, it might be capable of delivering drugs to IMS and matrix. Our group designed a GA-modified gelatin nanoparticle and it exhibited 4-fold higher cell internalization and 8.8-fold higher mitochondrial accumulation than GA unmodified nanoparticles in HepG2/ADR cells (details were introduced in next section) (Liu et al. 2019). These results revealed that GA is a novel potentially active ligand for both hepatocellular carcinoma and mitochondria targeting. However, whether GA had selectivity to mitochondria before it binds to respiratory chain in IMM and the mechanisms of how to realize this specificity remained to be further studied.

\section{Peptide-based mitochondrial targeted strategy}

Peptides are one of the prospective molecules for medical application and drug delivery owing to their physiological 
biocompatibility. Cell penetrating peptides such as TAT (RKKRRQRRR) and R8 (RRRRRRRR) are one of the most widely used peptides for enhanced cellular drug delivery (Frankel and Pabo 1988; Jones et al. 2005). Moreover, some endogenous or artificial peptides were confirmed to efficiently target mitochondria, and their potential for mitochondrial targeted drug delivery are introduced.

\section{Mitochondrial targeting sequences}

Although mtDNA itself could synthesize proteins, almost 99\% of all the mitochondrial proteins are translated in cytosolic ribosomes and then transported into mitochondria with the help of the natural mitochondrial targeting sequences (MTS) (Lu et al. 2016). Usually MTS are composed of 15-55 amino acids. In spite of no consistent sequence, they all possess the same structural characteristics such as an amphiphilic $\alpha$-helice, a lipophilic region on one side and a positive region on the other side. Firstly MTS enter into mitochondria via binding with the mitochondrial import machinery on OMM. After that, MTS choose to either interact with inner import machinery or stay at IMS to selectively deliver proteins to matrix, IMS or OMM ( $\mathrm{Lu}$ et al. 2016; Yamada and Harashima 2008). It is worth noting that although very prospective, MTS are too insoluble to pass through plasma membrane, which severely limits their intracellular application. Nevertheless, researchers found that combining MTS with cell penetrating peptides (CPP) could counteract the poor cellular uptake induced by MTS. Shokolenko et al. conjugated MTS and TAT to the ends of green fluorescent protein (GFP) and the MTS-GFPTAT showed enhanced cell internalization and mitochondrial accumulation (Shokolenko et al. 2005). Besides, they found that the N-terminal of MTS played an important role in mitochondrial recognition since N-decorated MTS were lack of mitochondrial targeting ability. Other reports also confirmed this feasible strategy (Del Gaizo and Mark Payne 2003; Lin et al. 2015). Recently, Klimpel et al. designed a hybrid peptide composed of CPP sC18 and MTS and found this bifunctional peptide exhibited remarkably promoted cellular uptake and mitochondrial matrix distribution for dozens of times compared to free MTS (Klimpel and Neundorf 2018). Furthermore, MTS-sC18 was proven to efficiently deliver chlorambucil into mitochondria, making it a promising candidate for mitochondrial targeted drug delivery.

\section{Mitochondrial penetrating peptides}

Mitochondrial penetrating peptides (MPP) is a kind of artificial peptide based on CPP which could efficiently penetrate mitochondrial double membranes. Due to the strongly negative charge of mitochondrial membranes, positively charged peptides are easily to enter into mitochondria. But differ from CPP, as IMM is more hydrophobic than plasma membrane, MPP are extra introduced with lipophilic amino acids to interact with IMM preferably. By making a balance between hydrophobic amino acid (cyclohexylalanine) and cationic amino acids (arginine and lysine), Horton et al. developed MPP with both high cellular uptake and mitochondrial matrix targeting capacity at the first time (Horton et al. 2008). Covalently conjugating MPP with anticancer drugs like cisplatin or DOX, it was found that MPP could change the intracellular distribution of drugs, making them mainly accumulate in mitochondria rather than nucleus. Further studies by PCR-based assay and fluorescence quenching confirmed that MPP could deliver drugs to mitochondrial matrix to damage mtDNA (Chamberlain et al. 2013; Fonseca et al. 2011; Wisnovsky et al. 2013). Moreover, we attached MPP to HPMA copolymer-DOX conjugate and it exhibited 11.6-fold higher mitochondrial accumulation (Zhou et al. 2019). The overall works implied that MPP could be utilized to deliver chemotherapeutics and nanosystems to mitochondria preferentially. Nevertheless, because of the strongly positive charge, its direct application in vivo is also limited.

\section{Szeto-Schiller peptides}

Szeto-Schiller (SS) peptides are a class of cell-permeable short peptides with antioxidative ability, generally composed of 4 amino acids (less than 10). Their structures are based on the alternating cationic and aromatic amino acids and have a D amino acid (Szeto 2006). The cellular uptake of SS peptides is concentration-dependent but energy-independent, which means they enter into cells via non-endocytosis pathway (Zhao et al. 2003). By isolating different subfraction of mitochondria through three cycles of freeze-thaw treatment and digitonin disruption, Zhao et al. found that SS peptides selectively target and concentrate more in IMM rather than in OMM or matrix (Zhao et al. 2004). The mechanism of mitochondrial targeting might be the electrostatic and hydrophobic interaction between SS peptides and cardiolipin in IMM. Owing to the tyrosine or dimethyltyrosine residue, SS peptides can scavenge peroxynitrite and hydrogen peroxide and inhibit lipid peroxidation. By reducing ROS, inhibiting mitochondrial permeability transition and cytochrome C release, SS peptides could prevent cell death induced by peroxidation (Zhao et al. 2004). Preclinical studies have shown their potential for neurodegenerative diseases and ischemia-reperfusion treatment (Zhao et al. 2004; Szeto 2008; Kezic et al. 2016). Notably, unlike most of mitochondrial targeted small molecules or peptides, SS peptides do not depend on the negative potential of IMM and have high accumulation even in depolarized mitochondria ( $\mathrm{Lu}$ et al. 2016). This is of great significance for treatment of diseases with mitochondrial disorders, making SS peptides 
an attractive candidate for mitochondrial targeted delivery, both for therapeutics and targeting.

\section{Vehicle-based mitochondrial targeted strategy}

In most cases, nanosystems achieve mitochondrial targeting by modifying targeting ligands. Notably, there are some carriers that are capable to target mitochondria by themselves. Compared to small molecules and peptides, these drug delivery systems possess better in vivo circulation and specific distribution. Besides, they can easily achieve mitochondrial targeting without complicated chemical modification, which makes them promising carriers for sub-cellular drug delivery.

\section{MITO-Porter}

Mitochondria have a double-membrane structure and maintain a dynamic balance of fusion and fission in physiological condition. Inspired by some unique characteristics of liposome, Yamada et al. designed a liposomal-based mitochondrial targeted nanocarrier MITO-Porter, which could deliver drugs into mitochondria by means of membrane fusion (Fig. 1) (Sato et al. 2016; Abe et al. 2016). MITO-Porter, owing to the cationic CPP octaarginine (R8) modification on the surface, was firstly taken up via macropinocytosis, and then bound to mitochondria by electrostatic interaction with negatively charged IMM, finally delivered cargos into IMS via membrane fusion. The authors screened the lipid compositions and found that when the liposomes were composed of dioleophosphatidyl ethanolamine (DOPE)/ phosphatidic acid (PA)/stearylated R8 (STR-R8) or DOPE/ sphingomyelin (SM)/STR-R8 [molar ratio 9:2:1], the nanocarrier exhibited the optimal mitochondrial fusion capacity. Besides, SM showed a lower toxicity than PA, implying that lipids containing SM were more suitable for drug delivery (Yamada et al. 2011). The authors verified that MITO-Porter successfully delivered antioxidant Coenzyme CoQ10 and aminoglycoside drug gentamicin to mitochondria, showing approximately 3-fold higher accumulation compared to non-fusion polyethylene glycol (PEG)-liposome and egg phosphatidylcholine (EPC)-liposome in liver and tumor mitochondria, respectively (Yamada et al. 2015; Abe et al. 2016). The authors speculated that this MITO-Porter strategy allowed efficient cargo delivery to mitochondria in a size- and physical properties-independent manner, making it a prospective nanocarrier for the treatment of mitochondrialrelated diseases (Sato et al. 2016).

\section{Mesoporous silicon nanoparticles}

Based on the fact that most of mitochondrial targeted strategies rely on the strongly negative charge of IMM, positively charged nanoparticles may also exhibit mitochondrial selectivity. Due to the large drug loading capability and multiple surface functionalization, mesoporous silicon nanoparticles (MSN) are competitive nanocarriers for drug delivery (Tang et al. 2012; Tarn et al. 2013). Previously, Luo et al. modified negatively charged MSN with TPP to target deliver antibiotic peptide (KLAKLAK) 2 to mitochondria (Luo et al. 2014). Considering that positive charge could be fulfilled via chemical modification, we developed a positively charged
Fig. 1 Mitochondrial targeted delivery of gentamicin derivative by MITO-Porter via membrane fusion. Reprinted with permission from reference (Abe et al. 2016)

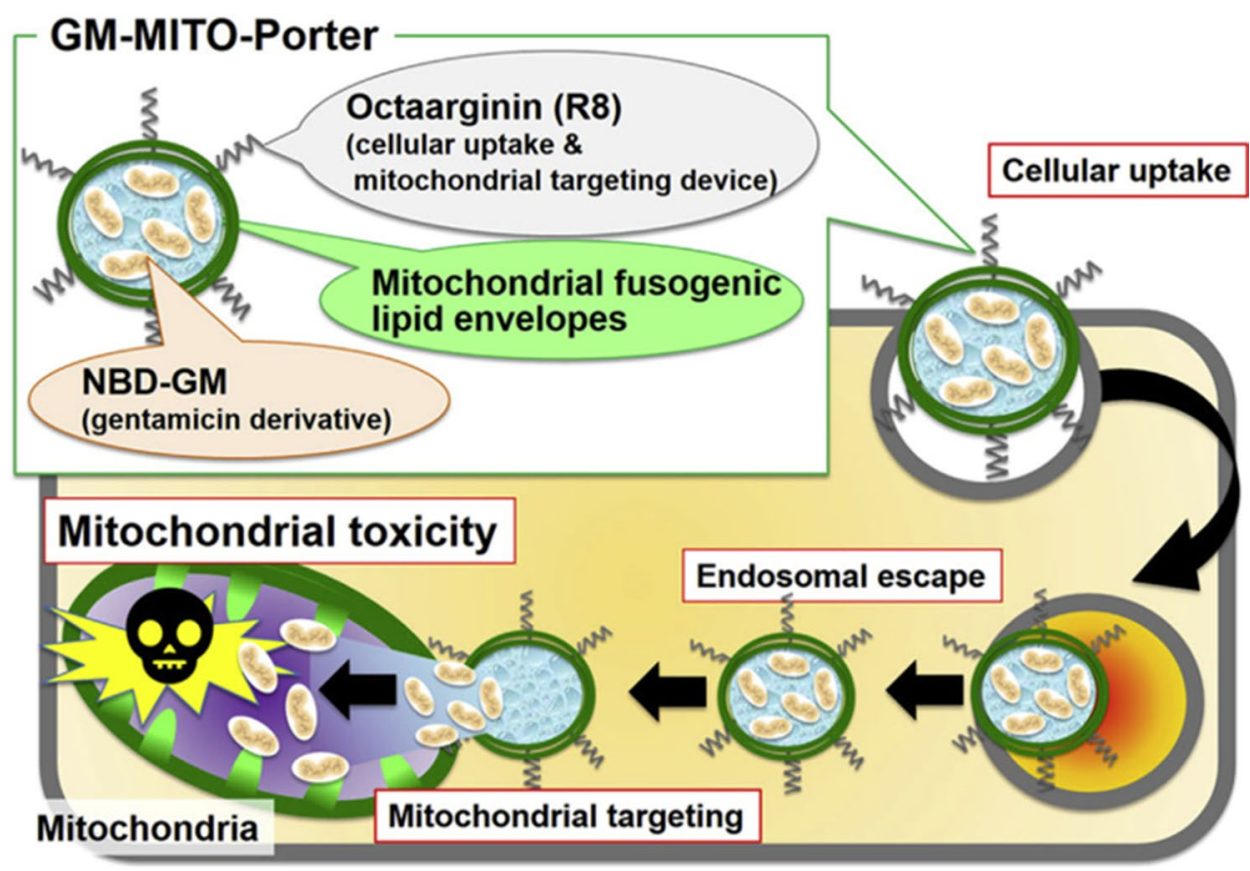


MSN with amine groups on the surface to targeted deliver docetaxel (DTX) to mitochondria (Fig. 1a) (Li et al. 2017). The zeta potential of MSN and MSN-DTX was $28.4 \mathrm{mV}$ and $27.4 \mathrm{mV}$, respectively. Owing to the negative-charged potential of plasma membrane and mitochondrial membranes, MSN-DTX showed superior cellular uptake and mitochondrial distribution in HeLa cells (details were introduced in next section). Notably, the physicochemical properties (e.g., charge, size, hydrophilicity) of MSN are variable via different formulations and modifications, allowing them a promising carrier for the investigation of diverse sub-cellular targeting.

For the moment, how to realize efficient mitochondrial accumulation is also a rough obstacle for mitochondrial targeted drug delivery. Though early mitochondrial targeting group-drug conjugates exhibited certain mitochondrial targeting and therapeutic efficacy both in vitro and in vivo, most of them possessed the shortcomings of poor water solubility, lack of tissue/cell selectivity and easily to be removed in blood circulation, which severely limited their clinical application (Banerjee et al. 2011). In the recent ten years, researchers have focused on developing mitochondrial targeted drug delivery systems to overcome a series of biological barriers in vivo, i.e. rapid blood clearance, low target accumulation, and low mitochondrial membrane penetration, with advantages of more tissue specificity, lower side effects and higher mitochondrial targeting abilities for cancer and other mitochondrial-related diseases treatment (e.g., Alzheimer's disease and kidney injury). In next sections, we mainly introduce the development and application of these delivery systems in multiple diseases in details.

\section{Application of mitochondrial targeted drug delivery systems for anti-cancer treatment}

Mitochondrial dysfunctions such as mtDNA mutation and high ROS level are closely associated with tumor generation (Wallace 2012; Zong et al. 2016). Besides, mitochondria are main regulator of intrinsic apoptosis pathway, a process that usually blocked in rapidly growth and resistant tumors (Fulda et al. 2010). Due to the key role of mitochondria in tumor progression, mitochondrial targeted antitumor therapy has been attracted considerable attention in recent years. Generally mitochondrial targeting is achieved by attaching targeting groups/ligands to drugs or dug-loaded carriers. However, since the tumor targeting efficiency of nanosystems is relatively low (only approximately $0.7 \%$ nanoparticles were found to be delivered to tumors), the amount of drugs that can localize into mitochondria is even poor (Wilhelm et al. 2016). What's more, positively charged nanosystems are easier to enter into mitochondria, whereas they are easily to be eliminated from blood circulation (Souris et al. 2010; Xiao et al. 2011). Herein, how to achieve more efficient mitochondrial targeting is also the main focus for mitochondrial targeted cancer treatment. In this section we discuss the application of effective mitochondrial targeted drug delivery systems for antitumor, including anti-drug resistance, anti-metastasis and immunotherapy (Table 2).

\section{Mitochondrial targeting for antitumor treatment}

Mitochondria are the center regulator of intrinsic apoptosis pathway, by regulating the balance of pro-apoptosis and antiapoptosis to induce programmed cell death. Under apoptotic stimuli like ROS production or $\mathrm{Ca}^{2+}$ release, mitochondria exert a sequence of events including the depolarization of inner membrane potential, mitochondrial swelling and the opening of MPTP. Once the OMM permeabilization occurs, cytochrome $\mathrm{C}$ is released from ISM to cytosol, activating downstream caspase cascade, consequently induce apoptosis (Yamada and Harashima 2008; Lu et al. 2016). Escaping from cell death is a hallmark of tumor cells, which is associated with apoptosis blockade. Therefore, drugs developed to promote apoptosis pathway may represent an effective strategy for anticancer treatment.

Paclitaxel (PTX) and DTX, usually used as microtubule inhibitors, were also found to activate mitochondrial intrinsic apoptosis by destabilizing mitochondrial membranes and opening MPTP (Varbiro et al. 2001; Mironov et al. 2005). Herein, we utilized positively charged MSN to targeted deliver DTX to mitochondria via electrostatic interaction (Li et al. 2017) (Fig. 2a). Owing to the negative potential of plasma membrane and mitochondrial membranes, MSNDTX showed highest cellular uptake and mitochondrial distribution. However, nanoparticles with positive charge were easily cleared by RES, making their tumor accumulation extremely limited. To overcome this problem, a pH-responsive $\mathrm{N}$-(2-hydroxypropyl) methacrylamide (HPMA) copolymer modified with anionic 2,3-dimethylmaleic anhydride (P-DMA) was developed by our group to coat on MSN-DTX via electrostatic effect to shield the amine groups. The zeta potential of R-P@MSN-DTX was - $18.2 \mathrm{mV}$, contributing to the enhanced stability in blood circulation (1.84-fold higher of $\mathrm{t}_{1 / 2}$ than MSN-DTX). After accumulating in tumor, HPMA copolymers experienced a charge switch from negative to positive in the acidic microenvironment, re-shielding the amine groups to mediate cell internalization and mitochondrial selectivity. This $\mathrm{pH}$-responsive MSN exhibited prominent mitochondrial accumulation (approximately 2.0fold higher than that of $\mathrm{pH}$-insensitive one at $\mathrm{pH}$ 6.5) and 2.82-fold higher ROS production as well as significant collapse of mitochondrial membrane potential $(\Delta \psi \mathrm{m})$, resulting in superior antitumor efficacy in vivo.

However, because of the extremely low permeability of mitochondrial membranes, it was assumed that molecules 


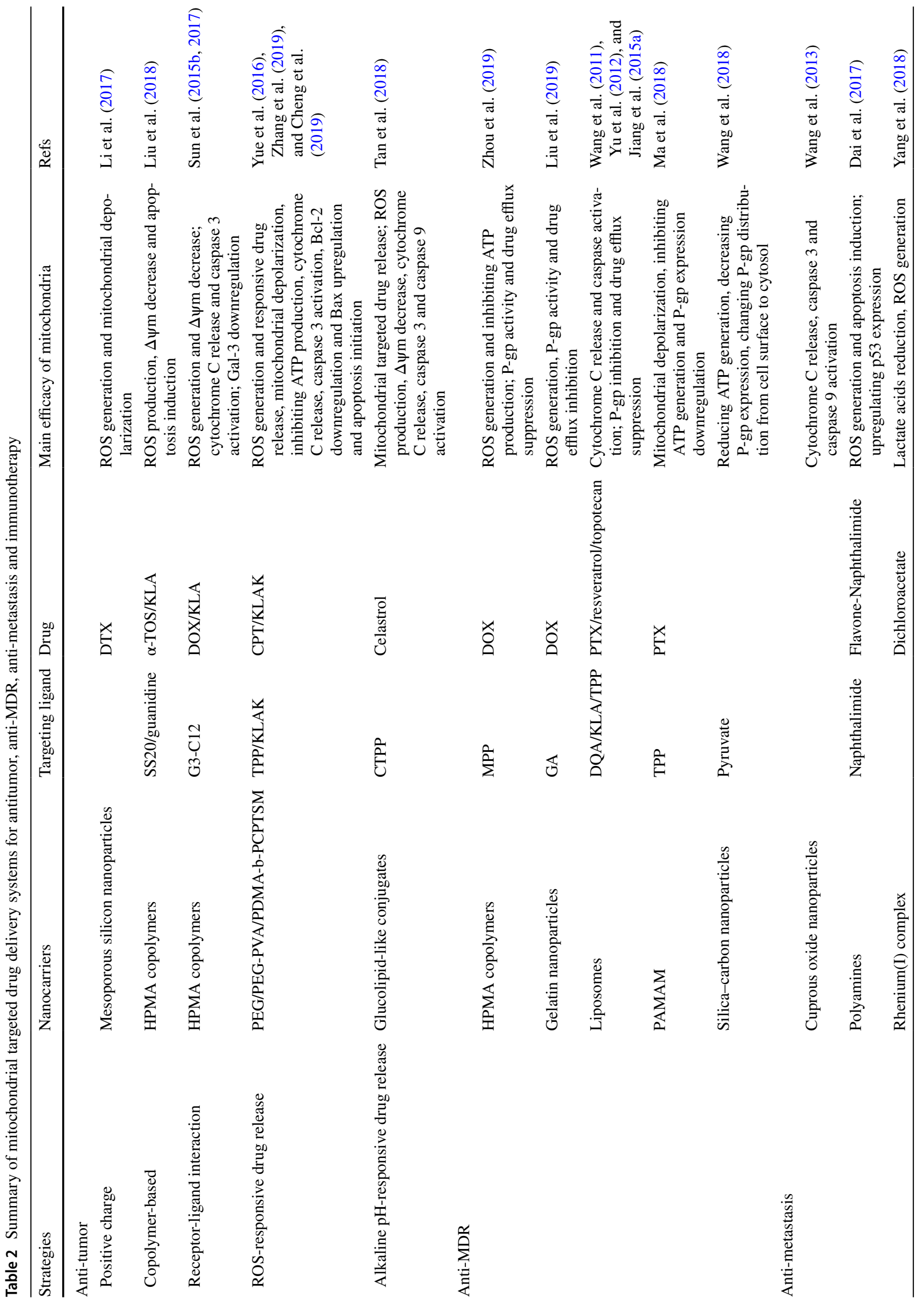


less than $5 \mathrm{kDa}$ could freely pass through OMM (Yamada and Harashima 2008). Therefore, mitochondrial-targeted systems with small size and molecular weight might achieve better mitochondrial accumulation. Based on this, polymers with small, flexible and easily modified structures are emerged as a good choice for organelle targeting. Our lab focuses on developing targeted drug delivery systems based on HPMA copolymers, a water-soluble carrier with advantages of biocompatibility, non-toxicity and non-immunogenicity. $\alpha$-Tocopheryl succinate ( $\alpha$-TOS), one of the vitamin $\mathrm{E}$ derivatives, is known to induce rapid ROS production via binding with coenzyme $\mathrm{Q}$ of mitochondrial respiratory complex II and activate apoptosis in cancer cells but has little toxicity to normal cells (Weber et al. 2003; Dong et al. 2008). However, owning to its poor water solubility and non-mitochondrial specific distribution, its practical application in cancer treatment has been quite limited. Hence, we designed a Szeto-Schiller peptide (SS20, Phe-D-ArgPheLys-NH2) modified HPMA copolymer- $\alpha$-TOS conjugate named as P-TOS-SS20-dNP2 to target deliver $\alpha$-TOS to tumor cell mitochondria (Liu et al. 2018). Since our previous study found that SS20 would promote the mitochondrial distribution (4.3-fold) but decrease the cellular uptake of HPMA copolymers, a human cell penetrating peptide dNP2 (CKIKKVKKKGRKKIKKVKKKGRK) was introduced to achieve better cell internalization and mitochondrial accumulation. Compared with unmodified copolymers, P-TOSSS20-dNP2 exhibited 7.6-fold higher mitochondrial distribution. Further study revealed that P-TOS-SS20-dNP2 showed more than 2-fold higher ROS production, which led to remarkable mitochondrial depolarization and improved antitumor efficacy.

Considering that lipophilic and positively charged small molecules such as TPP, guanidine could realize increased cellular and mitochondria uptake at the same time, we developed guanidine decorated HPMA copolymers loaded with a pro-apoptotic peptide KLA (P-GPMA-KLA) to specifically disrupt mitochondrial membrane and induce intrinsic apoptosis for cancer treatment (Wang et al. 2017). Then a $\mathrm{pH}$-responsive copolymer P-DMA was introduced to get the neutral nanocomplex (MPC) in order to shield the positive charge (Fig. 2b). Similarly, MPC could collapse at acidic tumor microenvironment, followed by the exposure of P-GPMA-KLA and its cellular trafficking. The intracellular study in B16F10 cells illustrated that the cellular uptake and mitochondrial distribution of P-GPMA-KLA were 4.27 -fold and 24.5-fold higher than non-decorated copolymer P-KLA, and that of MPC at pH 6.5 were 2.51-fold and 4.94-fold higher than $\mathrm{pH} 7.4$, respectively. Subsequently, MPC generated 3.19-fold higher ROS and showed 1.87-fold higher collapse of $\Delta \psi \mathrm{m}$ than that of P-KLA. Expectedly, MPC exhibited the best cytotoxicity (7.32-fold higher than P-KLA and much higher than free KLA) in vitro and antitumor capacity 
A
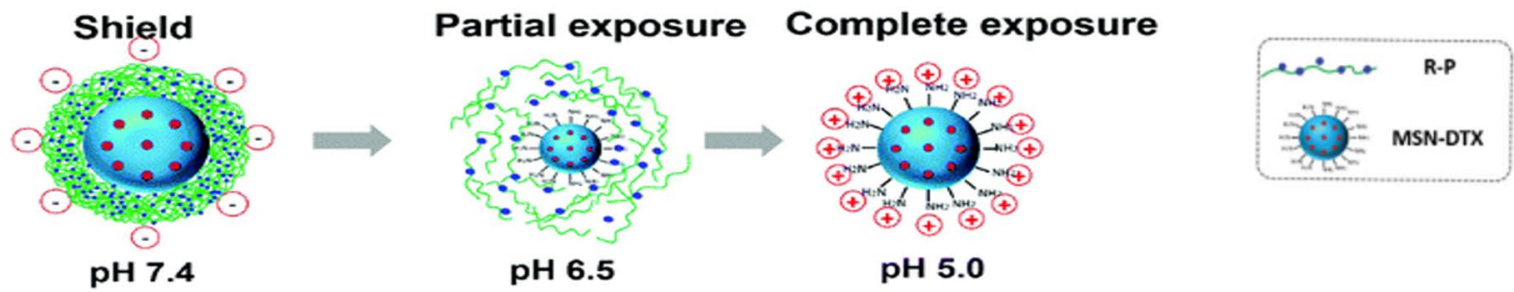

pH 6.5

pH 5.0

B
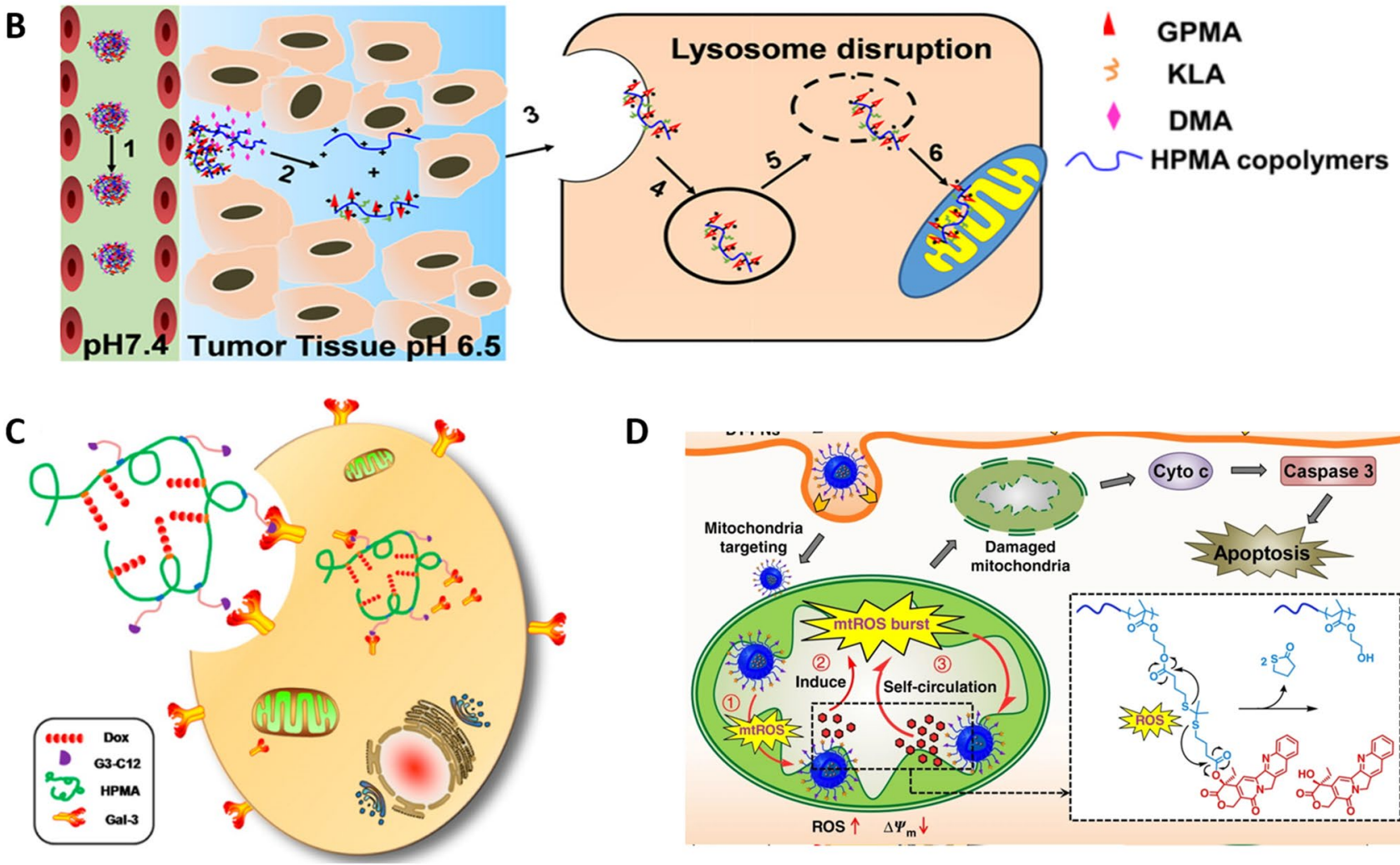

D

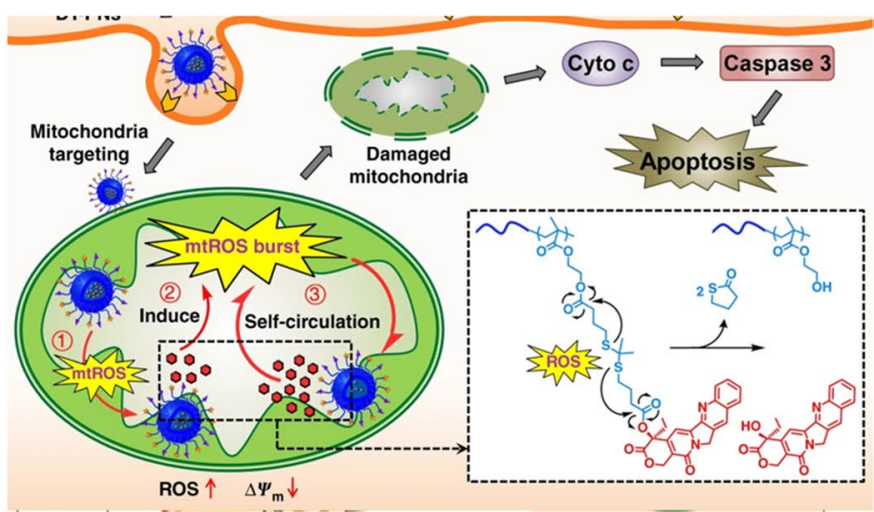

Fig. 2 Overview of multiple mitochondrial targeted drug delivery systems. a Core-shell mesoporous silicon nanoparticle (MSN) and its charge reversal at different $\mathrm{pH}$. Reprinted with permission from reference (Li et al. 2017). b In vivo transportation of the charge-reversible HPMA copolymer nanocomplex (MPC). Reprinted with permission from reference (Wang et al. 2017). c Active cell internalization and

(82.9\%) in B16F10 melanoma tumor-bearing C57 mice, revealing the prospective potential of mitochondrial targeted HPMA copolymers for tumor therapy.

Another mitochondrial targeted strategy we tried utilized receptor-ligand interaction. Galectin-3, which is overexpressed in multiple cancer cells, is involved in tumor progression, metastasis and anti-apoptosis. G3-C12, a binding peptide with high specificity towards galectin-3, was confirmed to promote cell internalization and antitumor ability of HPMA-5-fluorouracil copolymers in our previous study (Yang et al. 2012b, 2014). It was reported that in response to stimuli of pro-apoptotic drugs, a cell self-protection mechanism was initiated, with galectin-3 transferring from mitochondrial targeting of HPMA copolymer DOX conjugate mediated by the interaction between gelactin-3 and G3-C12 peptide. Reprinted with permission from reference (Sun et al. 2015b). d Mitochondrial targeting and specific drug release of polyprodrug nanoreactors with mtROS burst. Reprinted with permission from reference (Zhang et al. 2019)

nucleus or cytosol to mitochondria, inhibiting mitochondrial damage, cytochrome $\mathrm{C}$ release and cell apoptosis (Takenaka et al. 2004; Yu et al. 2002). Based on this, we assumed whether the post-stimuli galectin-3 could mediate mitochondrial targeted drug delivery. To confirm our hypothesis, we designed a G3-C12 modified HPMA copolymer DOX conjugate (G3-C12-HPMA-DOX) (Fig. 2c). After binding with G3-C12, galectin-3 transferred to mitochondria under the stimuli of DOX and delivered DOX to mitochondria at the same time (Sun et al. 2015b). Subsequently, G3-C12HPMA-DOX led to increased apoptosis with higher ROS production and expression of cytochrome $\mathrm{C}$ and $\mathrm{Bcl}-2$ than that of HPMA-DOX and free DOX. What's more, G3-C12 
downregulated the expression of galectin-3 (0.43-fold lower than control) and suppressed its anti-apoptotic effect. In vitro study indicated that G3-C12-HPMA-DOX exhibited 2.96fold higher cytotoxicity than HPMA-DOX in PC-3 cells. These findings revealed that G3-C12 could exert efficient cancer cell and mitochondria dual-targeted drug delivery, and eventually achieve excellent antitumor efficacy. Another drug delivery system P-G3-C12-KLA also confirmed this conclusion, showing outstanding tumor inhibition effect both in vitro and in vivo (Sun et al. 2017).

In spite of the development of multiple mitochondrial targeted systems for cancer therapy, drug leakage seems to be existed all the time from blood circulation to cellular mitochondria, causing unexpected side effects and reduced drug concentration. Herein, mitochondrial-specific drug release is emerged as a novel strategy to promote therapeutic effect. ROS is a kind of cell damage substance, as well as the main byproduct of mitochondrial oxidative phosphorylation, which could be utilized for mitochondrial-responsive drug release. Yue et al. covalently conjugated camptothecin (CPT) to one side of PEG via ROS-cleavable thioketal linker (TL) and mitochondrial targeted group TPP to the other side, then this copolymer was self-assembled to nanoparticle with photosensitizer Zinc phthalocyanine loaded in the inner core (ZnPc/CPT-TPP NPs). The nanoparticle selectively accumulated in mitochondria and destroyed mitochondrial membranes. Under near-infrared (NIR) irradiation, $\mathrm{ZnPc}$ produced ROS, followed by TL cleavage and native CPT release, resulting in the combination of photodynamic therapy (PDT) and chemotherapy for tumor treatment (Yue et al. 2016). It has been reported that ROS was over-produced in most tumor cells to meet their biological demand such as tumor progression and metastasis. Based on this, Zhang et al. utilized endogenous mitochondrial ROS (mtROS) to exert ROS-responsive CPT release (Fig. 2d). First the polyprodrug nanoreactors target mitochondria via TPP modification, then initial free CPT was released in the presence of endogenous mtROS. The released free CPT disrupted mitochondrial respiratory chain and increased mtROS generation, which in turn promoted more CPT release, realizing mtROS circulation burst and greater cytotoxicity (tumor growth inhibition 81\%) (Zhang et al. 2019). Similarly, Cheng et al. developed a ROS-responsive polymeric nanoparticle that could transform to nanofibers under the cleavage of mtROS around mitochondria, leading to the exposure of mitochondrial targeted cytotoxic peptide KLAK to enter into mitochondria and exhibit prominent tumor suppression capacity (Cheng et al. 2019).

In addition to mitochondrial products, mitochondrial microenvironment can also be used for responsive drug release. Some studies have reported that in mitochondria, it was a weakly alkaline $\mathrm{pH}$ environment (around $\mathrm{pH}$ 8.0) (Llopis et al. 1998; Matsuyama et al. 2000). Thus, Tan et al. designed a (4-Carboxybutyl) triphenylphosphonium bromide (CTPP) modified glucolipid-like conjugate selfassembled to load weakly acidic antitumor drug Celastrol (Cela) (Tan et al. 2018). The CTPP-CSOSA/Cela micelle targeted to mitochondria via lipophilic cation CTPP after enhanced cell internalization. Once reaching mitochondrial alkaline matrix, the solubility of acidic Cela was improved, leading to weaken interaction between hydrophobic core and Cela, followed by a fast drug release. The in vitro drug release experiment indicated that the micelle remained stable at $\mathrm{pH} 7.4$ and $\mathrm{pH}$ 5.0, nearly no drug leakage at $\mathrm{pH}$ 5.0, whereas a fast drug release occurred at $\mathrm{pH}$ 8.0. The specific drug release of CTPP-CSOSA/Cela led to a 3.2-fold higher ROS generation than free Cela, which caused stronger $\Delta \psi \mathrm{m}$ deceasing and more cytochrome $\mathrm{C}$ release. Further, CTPP-CSOSA/Cela showed a superior tumor suppression rate of $80.17 \%$, remarkably higher than that of CSOSA/Cela $(58.35 \%)$ and free Cela (54.89\%). This work proved that CTPP-CSOSA/Cela could achieve mitochondrial targeted drug delivery and specific drug release so that to obtain enhanced in vivo antitumor capacity.

\section{Mitochondrial targeting for overcoming multidrug resistance}

Multidrug resistance (MDR) is the inevitable result of longterm chemotherapy and a major obstacle to clinical treatment (Szakács et al. 2006; Chen et al. 2016). The mechanisms underlying MDR are complicated, generally divide into the acquired resistance including enhanced drug efflux, decreased cellular uptake, changes of drug targets and intrinsic resistance including blockade apoptosis and enhanced DNA repair (Patel et al. 2013; Holohan et al. 2013). Among all, drug efflux is the main cause of acquired resistance and has caught great concern in recent years (Gottesman et al. 2002). The tumor cell overexpressed ATP binding cassette (ABC) transporters, including ABCB1 (P-glycoprotein, P-gp), ABCC1 (MRP1) and ABCG2 (BCRP), pump drugs out to make the intracellular drug concentration sub-lethal. Many studies for overcoming MDR concentrated on decreasing the activity and expression of $\mathrm{ABC}$ transporters via small molecule inhibitors and gene silencing (Tang et al. 2016; To 2013). Notably, mitochondria play a crucial role in MDR (Saraswathy and Gong 2013). One the one hand, the process of drug efflux is ATP-dependent, while mitochondria are the major source of ATP and recognized as the "cellular powerhouse". On the other hand, mitochondria are the primary regulators of intrinsic apoptosis, which can lead to programmed cell death by activating caspasedependent or -independent pathways under stimuli of drugs or other substances (Zhou et al. 2019). In physiological condition, mitochondria keep a balance of membrane proapoptotic proteins (Bax, Bad) and anti-apoptotic proteins 
(Bcl-2, Bcl-XL) to maintain the necessary cell apoptosis and regeneration. However, in MDR cells, the anti-apoptotic proteins are upregulated and/or the pro-apoptotic proteins are downregulated. This imbalance contributes to the evasion of tumor cells from apoptosis and their survival. Taken together, destroying mitochondria to inhibit ATP production and activating apoptosis emerges to be an attractive strategy for overcoming MDR.

Previously, Han et al. covalently conjugated TPP to DOX and found that TPP-DOX could accumulate in mitochondria and exhibit a higher cytotoxicity than free DOX to reverse MDR (Han et al. 2014). Based on this, we rationally developed a mitochondrial targeted HPMA copolymer-DOX conjugate by modifying mitochondrial penetrating peptide MPP to DOX (P-M-DOX) (Fig. 3) (Zhou et al. 2019). It was reported that accumulated DOX in mitochondria could destroy mitochondrial respiratory chain components and increase ROS generation, initiating caspase cascades activation and cell apoptosis (Rogalska et al. 2008; Malhi et al. 2012). Owing to a balance between hydrophobicity and cation property, MPP exhibited high affinity with both plasma membrane and mitochondria. Compared with unmodified copolymer, P-M-DOX showed higher cellular uptake. After entering cells, the $\mathrm{pH}$-sensitive hydrazone bond broke down in lysosome, followed by the release of MPP-DOX to target to mitochondria (Fig. 3a, b). On the one hand, different from the passive diffusion of free drug, P-M-DOX was taken up via endocytosis, which bypassed P-gp to avoid drug efflux. On the other side, DOX targeted to mitochondria improved ROS production and activated intrinsic apoptosis. Moreover, the enhanced ROS stress inhibited ATP generation, causing suppression on P-gp activity and further less drug efflux, thus eventually overcoming MDR (Fig. 3c-e). Our results demonstrated that P-M-DOX exhibited superior resistance reversal ability in MCF-7/ADR cells (15.87-fold higher than DOX) and tumor spheroids anti-proliferation capacity (3.88-fold higher than DOX). Notably, this strategy directly delivered peptide-drug conjugate into mitochondria. Owing to its small molecular weight and spatial steric hindrance, it allowed more drugs to accumulate in mitochondria (11.6fold higher than unmodified one) compared with those whole targeted systems or native drugs released around mitochondria.

Unfortunately, the positive charge of P-M-DOX restricted its application in vivo. Considering that, another smart mitochondrial targeted nanoparticle was
A

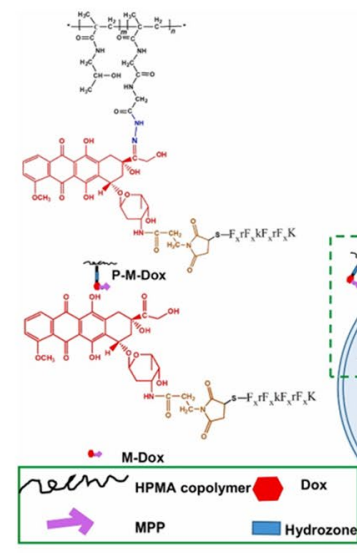

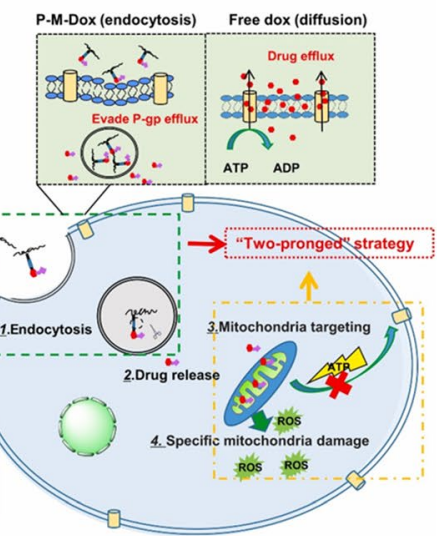

B

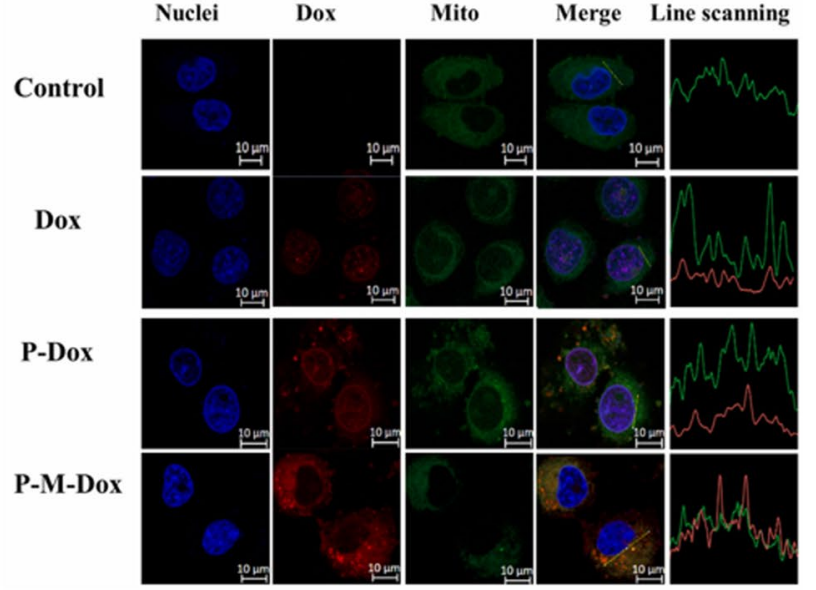

C

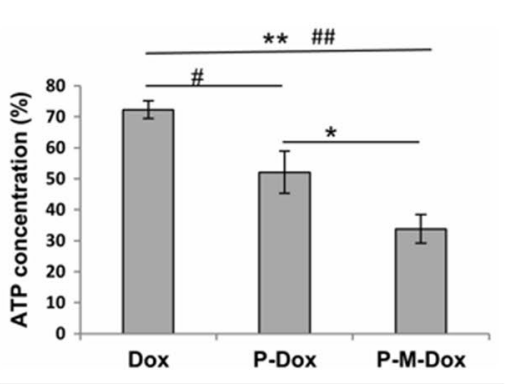

口MCF-7 口MCF-7/ADR

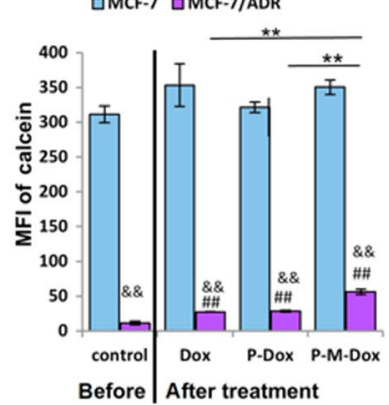

E

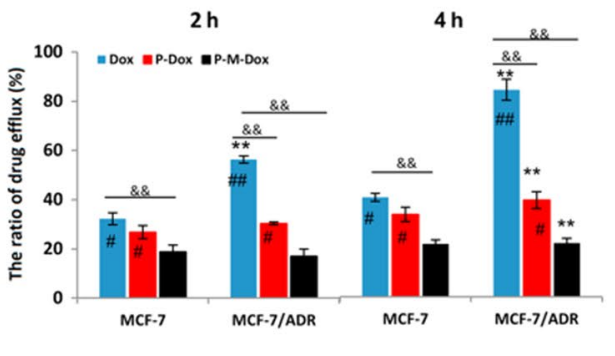

Fig. 3 a Schematic illustration of mitochondrial targeted P-MDox for overcoming MDR. The mechanisms of P-M-Dox to overcome MDR are simultaneously bypassing drug efflux and targeting mitochondria. b Mitochondrial colocalization analyzed by CLSM in MCF-7/ADR cells. Scale bar: $10 \mu \mathrm{m}$. c ATP generation, d P-gp activity and e drug efflux of each group in MCF-7/ADR cells by flow cytometry. Reprinted with permission from reference (Zhou et al. 2019) 
designed for better in vivo drug delivery (Liu et al. 2019). As HPMA copolymer with a small size was capable of achieving deeper tumor penetration but its blood stability and tumor accumulation were unsatisfactory, HPMA copolymers modified degradable gelatin nanoparticles (GNPs) was developed as a size-switchable carrier to realize both long circulation and deep penetration. Particularly, we chose glycyrrhetinic acid (GA) as the active ligand for both hepatocellular carcinoma cells (HCC) and mitochondria targeting due to its specific interaction with protein kinase $\mathrm{C} \alpha$ overexpressed on the HCC membranes and mitochondrial respiratory chain, respectively. DOX was firstly modified with GA and subsequently conjugated to HPMA copolymer via $\mathrm{pH}$-responsive hydrozone bond (P-DOX-GA). Later P-DOX-GA was grafted to the surface of GNPs to obtain GNPs-P-DOX-GA. Once reaching tumor, GNPs-P-DOX-GA was degraded by metal matrix protease-2 (MMP-2) to release P-DOX-GA for deep penetration and active targeting. After internalization, small molecule DOX-GA was further detached from HPMA copolymer in acidic lysosome and targeted to mitochondria. Our study showed that GNPs-P-DOX-GA exhibited almost 4-fold higher cellular uptake and 8.8 -fold higher mitochondrial distribution than GA unmodified nanoparticles in HepG2/ADR cells. With the excess ROS generation, GNPs-P-DOX-GA showed significantly decreased P-gp activity and drug efflux as well as the greatest tumor growth inhibition in vivo, implying its promising potential for MDR reverse and treatment.

Liposome is widely used as drug carrier due to its biocompatibility, easily for water-soluble and -insoluble drug delivery as well as decreased systemic cytotoxicity. Considering the high mitochondrial apoptosis stimulation but low water solubility and mitochondrial distribution of polyphenol drug resveratrol, Wang et al. modified delocalized lipophilic cation DQA on the surface of resveratrol-loaded liposome to target to mitochondria. The subcellular study showed a much higher mitochondrial colocalization of DQA-liposome than that of free drug and non-modified liposome. The released resveratrol induced mitochondrial depolarization and activated intrinsic apoptotic pathway to efficiently kill resistant lung cancer cells (Wang et al. 2011). Similarly, Jiang et al. grafted mitochondrial targeted pro-apoptotic peptide KLA onto liposome surface to deliver PTX to mitochondria, which could cause mitochondrial membrane disruption and apoptosis initiation, and finally overcome MDR (86.7\% inhibition of A549/Taxol tumor growth) (Jiang et al. 2015a). D-a-tocopheryl polyethylene glycol succinate (TPGS) is known as a P-gp inhibitor, researchers conjugated TPGS and mitochondrial targeted ligands (DQA/TPP) onto the surface of mitochondrial damage drug (topotecan/paclitaxel)-loaded liposomes (Yu et al. 2012; Zhou et al. 2013). By destabilizing mitochondrial membranes, promoting apoptosis and inhibiting P-gp drug efflux, the multifunctional liposomes were able to circumvent both acquired and intrinsic MDR.

What's more, other polymers and inorganic nanoparticles are also utilized for mitochondrial-related MDR reverse. Ma et al. constructed a novel glucose transporter-1 (GLUT1)-mediated and MMP2-responsive mitochondrial targeted dendrimer polymer GPp/TPP/PTX PAMAM, which showed long circulation in blood via PEG layer and enhanced internalization via interactions between glucose and GLUT-1 overexpressed on the membranes of resistant tumor cells. Subsequently, this polymer was delivered to mitochondria via TPP and PTX was released to cut off the energy supply, inhibiting P-gp drug efflux and consequently reversing MDR (Ma et al. 2018). He et al. combined mitochondrial targeting and PDT to overcome MDR (Wang et al. 2018). Pyruvate, which could specifically bind with the monocarboxylate transporters (MCTs) on the OMM, allowed the lipid membrane-coated inorganic silica-carbon nanoparticles (LSC NPs) selectively distribute in mitochondria. Under NIR irradiation, LSC NPs produced enormous ROS, which oxidized nicotinamide adenine dinucleotide hydrogen (NADH) to reduce ATP generation and compromise the activity of efflux pumps in drug resistant cells. Moreover, DOX-loaded LSC $\mathrm{NPs}+$ laser treatment downregulated P-gp expression and promoted its distribution in cytosol rather than on plasma membrane at the same time, thus to overcome MDR and achieve superior killing effects on resistant tumor cells and cancer stem-like cells (CSCs) both in vitro and in vivo.

Taken together, these works convincingly demonstrated that mitochondrial targeted therapy would indeed be a potential approach to overcome MDR.

\section{Mitochondrial targeting for anti-metastasis}

Almost more than $90 \%$ of cancer mortality in clinic are associated with tumor metastasis (Valastyan and Weinberg 2011; Jiang et al. 2015b). In 2018 global cancer statistics, metastatic breast cancer remained to be the leading mortality of female cancers over 100 countries (Bray et al. 2018). Yet many effective treatments have been developed to prevent and diagnose cancers in an early time, tumor metastasis suppression is still a difficult obstacle for clinical therapy (Steeg 2006; Valastyan and Weinberg 2011). Metastasis is a process of tumor cells detaching from primary site, crossing through extracellular matrix into blood circulation, and finally transferring to distant metastatic sites (Friedl and Wolf 2003). The mechanisms underlying metastasis are complex and mitochondria are closely associated with it.

Aerobic glycolysis is a hallmark of cancer. Even in an oxygen-sufficient condition, tumor cells preferentially undergo aerobic glycolysis rather than oxidative phosphorylation to meet their fast demand for ATP, called "Warburg effect" (Yamada and Harashima 2008; Lu et al. 2016). 
Certainly, tumor cells also display oxidative phosphorylation, and the proportion varies in different cell lines. ROS is the major byproduct of mitochondria, where oxidative phosphorylation occurs. The ROS level in tumor cells is much higher than in normal cells. A large number of literatures revealed the vital role of ROS in tumor metastasis, but whether its pro-metastasis or anti-metastasis effect is controversial. Mutations in mtDNA exist in most tumors. Some mutations promote tumor metastasis, partially because of ROS generation (Kulawiec et al. 2014). Pre-treatment with ROS scavengers could decrease the potential of metastasis in high-metastatic tumor cells (Ishikawa et al. 2008). In addition, researchers found that compared with primary tumor cells, high-metastatic tumor cells and circulating cancer cells (CTCs) exhibited enhanced oxidative phosphorylation and ROS generation, demonstrating that ROS might increase metastasis, whereas downregulation of ROS level might inhibit tumor progression and metastasis (LeBleu et al. 2014; Sotgia et al. 2012). However, clinical trials treated with antioxidants has mostly failed, and even promoted metastasis (Peiris-Pages et al. 2015). Meanwhile, some studies found that ROS produced from oxidative phosphorylation showed an anti-metastatic effect (Lu et al. 2015), and wild-type anti-metastatic gene KISS1 as well as pyruvate dehydrogenase kinase (PDK) inhibited tumor metastasis by increasing oxidative phosphorylation (Liu et al. 2013; Kamarajugadda et al. 2012). Moreover, Piskounova et al. found that injection of ROS scavenger in vivo improved the number of CTCs and metastatic burden, whereas oxidative stress suppressed distant metastasis in human melanoma. For these results opposite to previous researches, they demonstrated that successful cell metastasis not only depended on high ROS level but also the matched high antioxidative efficacy. Utilizing antioxidants exhibited enhanced metastasis, whereas inhibiting antioxidative pathways suppressed metastasis (Piskounova et al. 2015). Furthermore, this high ROS level in tumor cells was also moderate. Enormous ROS generation by endogenous stimuli would in turn inhibit metastasis, which might be associated to gene damages and intrinsic apoptosis. Nevertheless, some reports also showed anti-metastasis by oxidative stress suppression. For this, they explained that only specific mitochondrial targeted oxidants could efficiently reduce the main source of cell oxidative stress (mtROS) and inhibit metastasis. Unfortunately, most of oxidants were lack of mitochondrial selectivity so that they failed in clinical trials (Peiris-Pages et al. 2015). All in all, mtROS indeed played a crucial role in tumor metastasis, but this role is two-sided.

Another metastasis associated regulator in mitochondria is Bcl-2 family proteins. As mentioned above, Bcl-2 family participates in regulation of apoptosis, possessing pro-apoptotic and anti-apoptotic effects. In addition, some studies reported that Bcl-2 family was also associated with metastasis, of which cells overexpressed anti-apoptotic proteins like Bcl-2 and $\mathrm{Bcl}-\mathrm{X}_{\mathrm{L}}$ showed high metastatic potential. Knockout of these genes efficiently reduced their metastasis (Um 2016). The mechanisms remain to be unclear, perhaps correlated with the activation of transcription factor activator protein 1 (AP-1) and upregulation of endothelial growth factor receptor (EGFR) and MMPs (Choi et al. 2005). It was worth noting that the pro-metastatic capacity of Bcl-2 family members seemed to vary in different cell lines, for example, knockout of Bcl- $\mathrm{X}_{\mathrm{L}}$ significantly reduced metastasis in breast cancer cells but had no remarkable influence on pancreatic cancer cells (Um 2016).

Herein, drug delivery targeting the function and metabolism of mitochondria appears to be a feasible anti-metastatic strategy. While investigating the antitumor effects of metal oxide nanoparticles, Wang et al. found that the cuprous oxide nanoparticles (CONPs) without chemical modification could selectively distribute in tumor cell mitochondria (Wang et al. 2012). After that, CONPs caused cytochrome $C$ release and activated caspase- 3 and caspase- 9 , resulting in lung metastasis suppression of melanoma B16F10 cells in vivo (Wang et al. 2013). Dai et al. designed a dual functional conjugates flavone-naphthalimide-polyamine with bioimaging and anti-metastasis properties. Due to the specific feature of some naphthalimides (a kind of DNA intercalator) which could alternatively distribute in other organelles rather than nucleus, this novel fluorescent derivative preferentially localized in mitochondria, causing more than 2-fold higher ROS production and remarkably decreased lung metastasis of hepatoma cells in vivo (Dai et al. 2017).

In addition to directly destroy the functions of mitochondria, targeting cancer mitochondrial metabolism can also realize metastasis suppression. The overproduced lactate acids by aerobic glycolysis were recognized as the promoter of tumor angiogenesis and invasion. Herein, targeting mitochondria and reversing cell metabolism from aerobic glycolysis to oxidative phosphorylation may successfully suppress tumor metastasis. Dichloroacetate (DCA), a typical mitochondrial metabolism reversing agent, could effectively inhibit the activity of pyruvate dehydrogenase kinase, promoting the conversion of pyruvate to acetyl-CoA and subsequent oxidative phosphorylation (Stockwin et al. 2010; Zhang et al. 2015). However, due to the insufficient mitochondrial accumulation of DCA, its therapeutic efficacy is limited. Based on these, Yang et al. developed a Rhenium (I)- DCA conjugate to targeted deliver DCA to mitochondria. By regulating the ligand and lipophilicity, this Rhenium (I) complex could rapidly penetrate through plasma membrane and mitochondrial membranes. The results indicated that Rhenium (I)- DCA conjugate efficiently decreased lactate acids secretion, enhanced ROS generation and suppressed tumor metastasis (Yang et al. 2018). Moreover, Huo et al. demonstrated a metabolism-based, both mitochondria 
and nucleus dual-targeted system Mito (T) -pep-Nuc (T) to ablate liver metastasized cancer cells (Fig. 4a). In tumor cells, TPP modified photosentizer (Ce6)-loaded MSNs and nuclear localization sequence functionalized $\mathrm{W}_{18} \mathrm{O}_{49}$ nanoparticles were released from Mito(T)-pep-Nuc(T) to simultaneously target mitochondria (Fig. 4b) and nucleus, causing PDT and photothermal therapy (PTT) under irradiation, respectively. In this way, Mito(T)-pep-Nuc(T) inhibited oxidative phosphorylation via singlet oxygen species generation and glycolysis via down-regulation of glycolysis-associated enzymes to cut off energy supply and depleted ATP at the same time (Fig. 4c, d), which exhibited prominent liver antimetastatic efficacy in vivo (Fig. 4e). Interestingly, because of the consumption of singlet oxygen species by $\mathrm{W}_{18} \mathrm{O}_{49}$ nanoparticles, Mito(T)-pep-Nuc(T) would not induce PDT and PTT in hepatocytes, ensuring its safety in normal tissues (Huo et al. 2019). Our group is also carrying out researches on mitochondrial targeted anti-metastasis, through targeting therapeutics to mitochondria to increase ROS level and downregulate metastasis-related cytokines and pathways.

\section{Mitochondrial targeting for immunotherapy}

In fact, our system can recognize and phagocytize foreign substances and abnormal cells. However, tumor cells can easily escape from immune system to survive. One of the reasons is the PD-1/PD-L1 checkpoint (Hamanishi et al. 2016; Dunn et al. 2002). The overexpressed PD-L1 on the surface of tumor cells can bind to PD- 1 of T cells, thus limits the interaction between antigen-presenting cells (APC) and $\mathrm{T}$ cell receptors and inhibits attack of $\mathrm{T}$ cells on tumors. PD-1/PD-L1 checkpoint blockade, by using PD-1 or PD-L1 monoclonal antibody to block immune suppressive pathway, can release and reactivate cytotoxic $\mathrm{T}$ cells to realize tumor cytotoxicity (Moreno and Ribas 2015; Meng et al. 2015; Alsaab et al. 2017). Recent studies on checkpoint blockade have achieved certain progress in clinic, and several monoclonal antibodies such as durvalumab, pembrolizumab and nivolumab have been approved by FDA for treatment of non-small cell lung cancer and melanoma. However, due to their severe immune-related side effects and high production costs, few patients benefit from this strategy and its application in clinic is still limited (Yang et al. 2019; Yu et al. 2019).

Recently, researchers have proved that besides PD-L1, tumor cells could also inhibit $\mathrm{T}$ cell infiltration and activation via immunosuppressive microenvironment (Jiang et al. 2015c). There have been some reports showing that $\mathrm{T}$ cell metabolism was a key regulator for its self-activation and effector function (Delgoffe and Powell 2015; Scharping et al. 2016). Scharping et al. found that in tumor microenvironment, the mitochondrial metabolism of $\mathrm{T}$ cells was
A
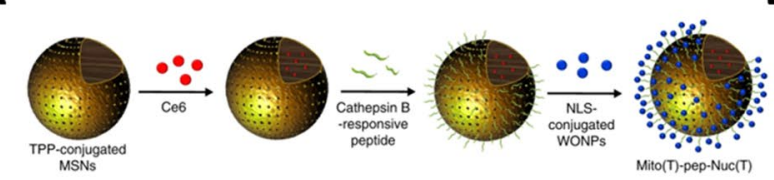

B
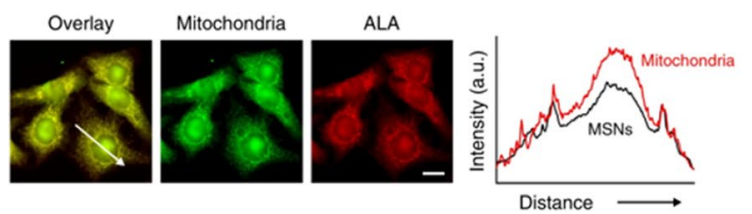

C

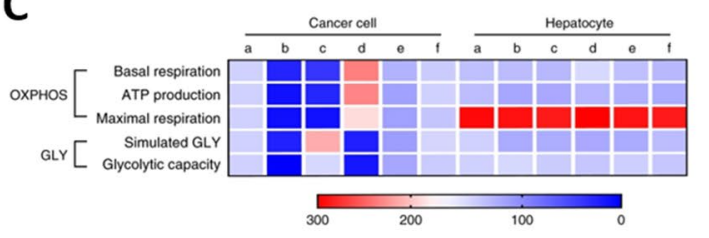

Fig. 4 Overview of the mitochondria and nucleus dual-targeted nanoparticles Mito(T)-pep-Nuc(T) for liver metastasis suppression. a Synthesis and preparation of Mito(T)-pep-Nuc(T). b Mitochondrial colocalization of Mito(T)-pep-Nuc(T) in HCT-116 cells. Scale bar: $10 \mu \mathrm{m}$. c A heat-map showing the values of basal respiration, ATP production, maximal respiration, and the simulated glycolysis (GLY)
D

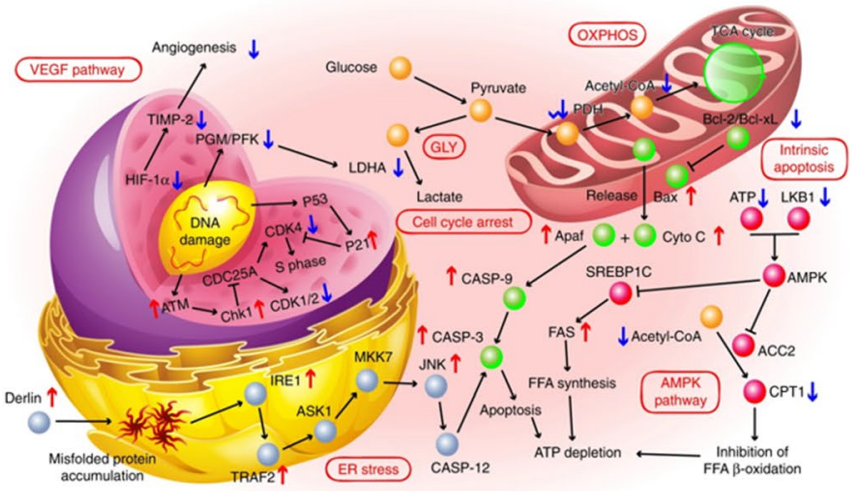

E
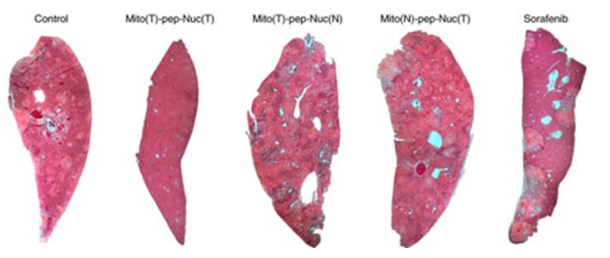

and glycolytic capacity that were respectively associated with oxidative phosphorylation (OXPHOS) and GLY. d A network of speculated pathways of Mito(T)-pep-Nuc(T) for anti-metastasis. e Exo vivo necropsy of liver tissues with different treatments at day 30 . Reprinted with permission from reference (Huo et al. 2019) 
suppressed, which was characterized by decreased mitochondrial mass, reduced biogenesis and glucose uptake, inhibited oxidative phosphorylation and ATP production, thus led to insufficiency of proliferation, differentiation and cancer killing effect of $\mathrm{T}$ cells, calling " $\mathrm{T}$ cell exhaustion" (Fig. 5a, b) (Scharping et al. 2016). This repressed biogenesis was, at least in part, related to the downregulation of PPAR-gamma coactivator $1 \alpha(\mathrm{PGC}-1 \alpha)$ via Aktmediated pathway but independent with PD-1 checkpoint regulation. Reprogramming PGC- $1 \alpha$ improved mitochondrial mass and function (Fig. 5c), consequently enhanced immunocompetence and antitumor efficacy. Furthermore, they demonstrated that 4-1BB, one of the costimulatory molecules in TNFR family, was able to upregulate PGC- $1 \alpha$ and promote mitochondrial biogenesis and function, leading to enhanced tumor immunotherapeutic responses (Menk et al. 2018). Chamoto et al. confirmed that the ROS precursors and uncouplers activated and expanded mitochondria via ROS generation, sequentially activated PGC- $1 \alpha$ through

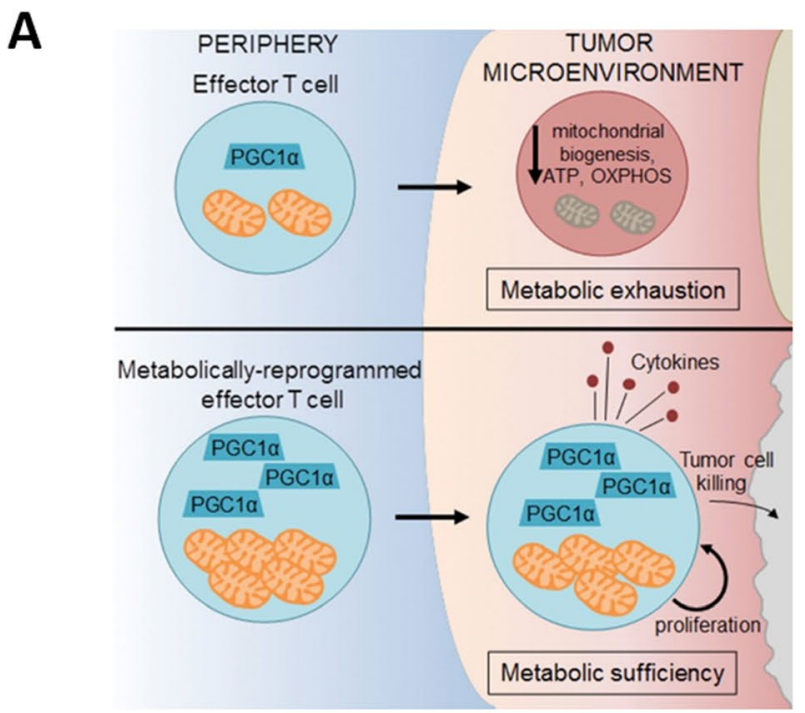

B

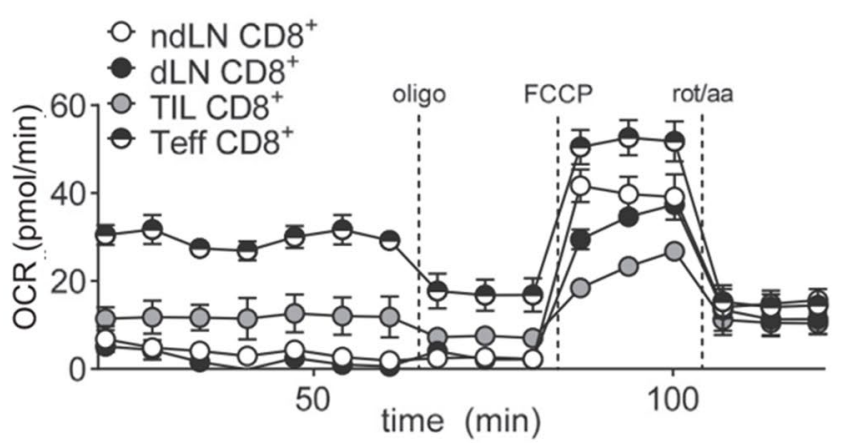

mechanistic target of rapamycin (mTOR) and AMP-activated protein kinase (AMPK) activation, thus reactivated $\mathrm{T}$ cells to exhibit synergistic antitumor capacity with PD-1 monoclonal antibody, which had no concern with ROS toxicity. Some chemical activators of mTOR and AMPK such as bezafibrate and oltipraz could also realize similar efficacy (Chamoto et al. 2017). Therefore, regulating and restoring mitochondrial metabolism of $\mathrm{T}$ cells seems to be an effective approach to increase cancer immunotherapy. However, little research of mitochondrial targeted drug delivery system in this field has been reported so far.

In addition to the auto-recognition of immune system, damaged cells also secrete signals that increase recognition by immune system to induce immunogenic cell death (ICD). These signals, called damage-associated molecular patterns (DAMPs), include calreticulin (CRT) translocation from endoplasmic reticulum (ER) to cell surface, ATP secretion and nuclear high-mobility group box 1 protein (HMGB1) secretion to extracellular matrix (Wong 2018). Two essential

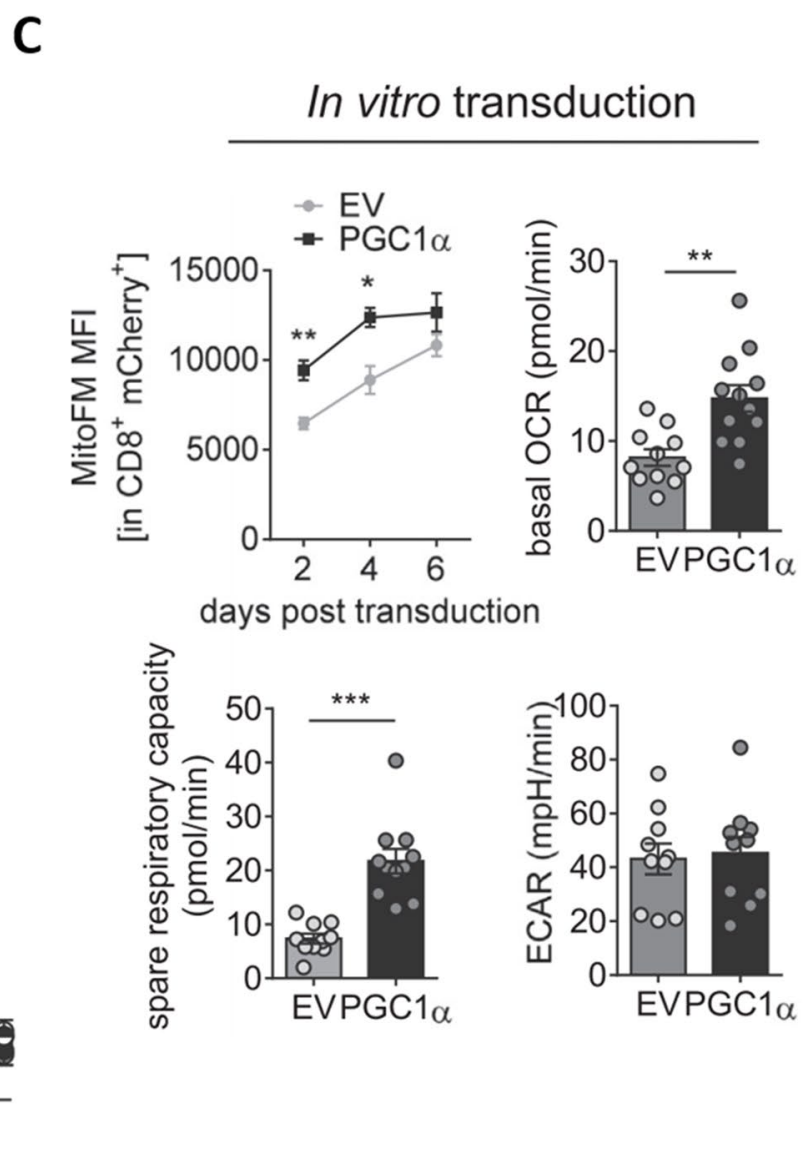

Fig. 5 a Schematic illustration of "T cell exhaustion" in tumor microenvironment. b Oxygen consumption rate (OCR) trace from CD8+T cells isolated from the indicated sites from B16-bearing animals. $\mathrm{T}$ cells activated $24 \mathrm{~h}$ with anti-CD3/anti-CD28 (Teff) are included as a control. c Metabolic analysis of OT-I T cells with PGC- $1 \alpha$ repro- gramming or empty-vector transduction. MitoTracker FM staining at various time points post transduction is indicated. OCR, spare respiratory capacity (SRC), and extracellular acidification rate (ECAR) values are from day 5-7 post transduction. Reprinted with permission from reference (Scharping et al. 2016) 
components of ICD are ROS production and ER stress, both are indispensable (Krysko et al. 2012). Although ER-based ROS generation can cause stronger ER stress and ICD, ER-indirect ROS can also realize ICD initiation (Garg and Agostinis 2014; Chen et al. 2019). Evidences showed that enhanced intracellular but not ER-specific ROS level by clostridium difficile toxin B and non-thermal plasma could lead to efficient ICD (Sun et al. 2015a; Lin et al. 2017). Mitochondria are the main source of intracellular ROS, therefore mtROS may be utilized for ICD induction.

Marrache et al. developed a mitochondrial-targeted, lightactivated nanoparticle as an antigen to stimulate dendritic cells (DCs). TPP was conjugated to PLGA-b-PEG polymer to targeted deliver photosensitizer zinc phthalocyanine to mitochondria (T-ZnPc-NPs). After laser irradiation, it generated enormous mtROS, which promoted interferon-gamma (IFN- $\gamma$ ) release from DCs in vitro, enabling potential immune activation in vivo for cancer immunotherapy (Marrache et al. 2013). Chen et al. designed a mitochondrial-targeted photosensitizer (TPE-DPA-TCyP) to induce oxidative stress focused mitochondria. Due to the strongly positive charge of pyridinium, TPE-DPA-TCyP was enabled to aggregate in mitochondria through electrostatic interaction. The results demonstrated that this mitochondrial targeted ROS generation was an effective strategy to burst large-scale ICD by inducing ectoCRT expression, ATP and HMGB1 secretion, and trigger both innate and adaptive immune system to realize excellent tumor inhibition (87.0\%) in vivo (Chen et al. 2019). Although this novel photosensitizer was not carried out with a nanocarrier, this research revealed the relationship between mitochondrial oxidative stress and ICD for the first time, implying the availability of mitochondrial targeting for immunotherapy.

Taken together, though little is known about the role of mitochondria in immune response so far, we speculate that mitochondrial targeted immunotherapeutic strategies, both targeting immune cells and tumor cells, are promising application for cancer treatment in the future.

\section{Application of mitochondrial targeted drug delivery systems for other diseases treatment}

Increasing researches revealed that mitochondrial dysfunction correlated with the development of diabetes (Lowell and Shulman 2005; Szendroedi et al. 2011), Alzheimer's disease (AD) (Chan 2006), kidney injury (Hall and Schuh 2016; Hallan and Sharma 2016), NAFLD (Sanyal et al. 2001; Wei et al. 2008) and their complications, of which oxidative stress was the major cause of cell damage and inflammation (Ha and Lee 2001). Numerous reports covalently conjugating antioxidants such as vitamin $\mathrm{E}$ and $\mathrm{CoQ}_{10}$ to TPP and found that they could specifically distribute in mitochondria and attenuate oxidative stress, exhibiting certain therapeutic efficacy in acute kidney injury and NAFLD both in vitro and in vivo (Ajith 2014; Dare et al. 2015).

In recent years, targeted nanosystems have also been developed for mitochondrial-related diseases study. It was confirmed that ceria nanoparticles (CeNPs) smaller than $5 \mathrm{~nm}$ could reversibly bind to oxygen atoms to scavenge ROS. Herein, Kwon et al. designed TPP modified CeNPs (TPPCe NPs) to selectively remove mtROS and reduce oxidative stress (Fig. 6a). The real-time confocal microscopy revealed that TPP-Ce NPs had an increased co-localization with mitochondria with time and it saturated at $10 \mathrm{~h}$ (Fig. 6b). The mtROS level study showed that TPP-Ce NPs remarkably decreased amyloid beta (A $\beta$ )-induced mtROS in SH-SY5Y neuronal cells (Fig. 6c). Subsequently the reduced oxidative stress mitigated morphological mitochondria damage and reactive gliosis as well as neuronal loss, thus to alleviate $\mathrm{AD}$ (Fig. 6d) (Kwon et al. 2016). Ling et al. combined the ROS scavenging capacity of ceria nanocrystals with methylene blue (an inhibitor of tau) and antagomiR-26a (an inhibitor of antiangiogenesis miRNA) for AD treatment and diabetic wound healing, respectively (Chen et al. 2018; Wu et al. 2019).

Besides, Tian et al. developed a pH-responsive nanoparticle loaded with ABT-199, a Bcl-2 protein inhibitor, to alleviates allergic asthma (Nf-ABT-199). Once reaching lysosome, this nanoparticle underwent a charge reversal from negative to positive, contributing to lysosomal escape and mitochondrial targeting, sequentially promoted apoptosis of airway inflammatory cells. Moreover, (Nf-ABT-199) was proved to inhibit mucus hypersecretion and inflammatory cell infiltration, consequently attenuate allergic asthma. What's more, (Nf-ABT-199) was found to cause no obvious toxicity on airway epithelial and liver in vivo, making it a safe and efficient nanoformulation for allergic asthma treatment (Tian et al. 2019).

To sum up, these works indicate that targeted delivering drugs to reverse mitochondrial dysfunction acts as an efficient approach for treatment of other mitochondrial-related diseases. In future, more efforts and attempts need to be put in this field for further study.

\section{Conclusion}

Owing to the vital role of mitochondria in a variety of diseases, mitochondrial-targeted diseases treatment, especially for cancer, has attracted more attention and achieved certain breakthrough so far (Battogtokh et al. 2018). However, some issues for mitochondrial targeting should also be pointed out. Although multiple strategies are utilized for promoting mitochondrial targeting, the amount of drugs that can first accumulate in target cells and then localize in mitochondria is still very low (Wilhelm et al. 2016). To further improve 


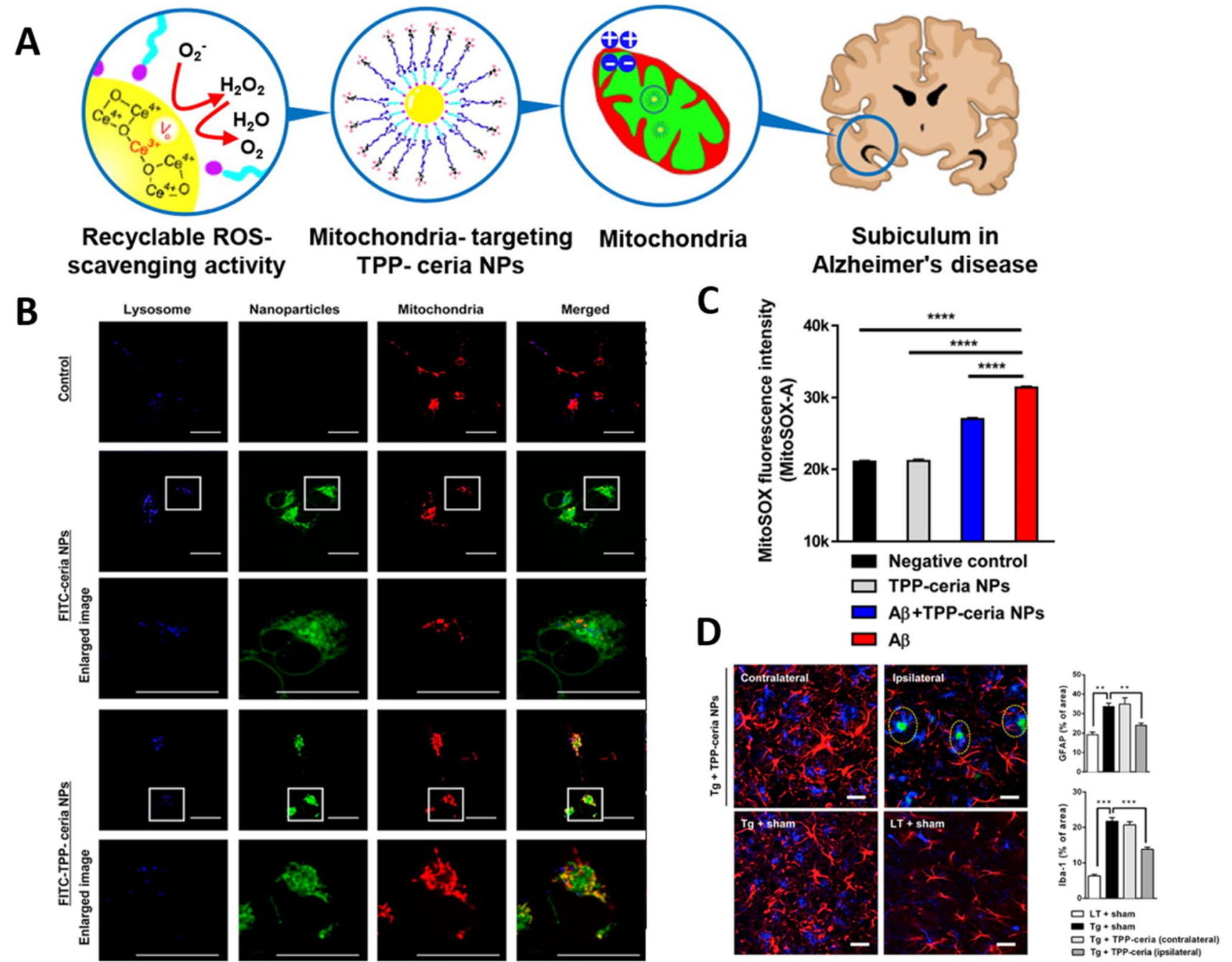

Fig. 6 a Schematic illustration of mitochondrial targeted TPP-CeNPs for AD treatment. b Mitochondrial colocalization of TPP-CeNPs inSHSY5Y cells observed by CLSM. Scale bar: $20 \mu \mathrm{m}$. c ROS level of SHSY5Y cells treated with different groups by flow cytometry. d
CLSM images of gliosis and the quantified level of brain tissues in AD-model mice. Reprinted with permission from reference (Kwon et al. 2016)

of mitochondrial targeting in drug delivery systems should be further studied to guide the design of systems in turn.

Finally, since the onset of diseases is a complex physiological network, combination therapy emerges to be the current trend of disease treatment in clinical (Fitzgerald et al. 2006; Ghosh et al. 2018). Mitochondrial targeting combined with PDT, nuclear targeting, immunotherapy or other means has made some progress in basic researches (Wang et al. 2018; Huo et al. 2019; Chen et al. 2019). We hope that more in-depth studies would be established on the design and application of mitochondrial targeted combination therapy in the future. And the most important, it should also be connected with clinical practice.

Acknowledgements The authors gratefully acknowledge financial support from the National Natural Science Foundation for Distinguished Young Scholars (81625023) and 111 project (b18035). 


\section{Compliance with ethical standards}

Conflict of interest The authors declare that they have no conflict of interest.

Statement of human and animal rights This article does not contain any studies with human and animal subjects performed by any of the authors.

Open Access This article is licensed under a Creative Commons Attribution 4.0 International License, which permits use, sharing, adaptation, distribution and reproduction in any medium or format, as long as you give appropriate credit to the original author(s) and the source, provide a link to the Creative Commons licence, and indicate if changes were made. The images or other third party material in this article are included in the article's Creative Commons licence, unless indicated otherwise in a credit line to the material. If material is not included in the article's Creative Commons licence and your intended use is not permitted by statutory regulation or exceeds the permitted use, you will need to obtain permission directly from the copyright holder. To view a copy of this licence, visit http://creativecommons.org/licenses/by/4.0/.

\section{References}

Abe J, Yamada Y, Harashima H (2016) Validation of a strategy for cancer therapy: delivering aminoglycoside drugs to mitochondria in hela cells. J Pharm Sci 105(2):734-740. https://doi.org/10.1002/ jps. 24686

Ajith TA (2014) Mitochondria-targeted agents: future perspectives of mitochondrial pharmaceutics in cardiovascular diseases. World J Cardiol 6(10):1091. https://doi.org/10.4330/wjc.v6.i10.1091

Alsaab HO, Sau S, Alzhrani R, Tatiparti K, Bhise K, Kashaw SK, Iyer AK (2017) PD-1 and PD-L1 checkpoint signaling inhibition for cancer immunotherapy: mechanism, combinations, and clinical outcome. Front Pharmacol 8:561

Banerjee D, Harfouche R, Sengupta S (2011) Nanotechnology-mediated targeting of tumor angiogenesis. Vasc Cell 3(1):3

Battogtokh G, Cho Y-Y, Lee JY, Lee HS, Kang HC (2018) Mitochondrial-targeting anticancer agent conjugates and nanocarrier systems for cancer treatment. Front Pharmacol. https://doi. org/10.3389/fphar.2018.00922

Bray F, Ferlay J, Soerjomataram I, Siegel RL, Torre LA, Jemal A (2018) Global cancer statistics 2018: GLOBOCAN estimates of incidence and MORTALITY worldwide for 36 cancers in 185 countries. CA Cancer J Clin 68(6):394-424. https://doi. org/10.3322/caac. 21492

Brown SE, Ross MF, Sanjuan-Pla A, Manas A-RB, Smith RAJ, Murphy MP (2007) Targeting lipoic acid to mitochondria: synthesis and characterization of a triphenylphosphonium-conjugated $\alpha$-lipoyl derivative. Free Radical Biol Med 42(12):1766-1780. https://doi.org/10.1016/j.freeradbiomed.2007.02.033

Chamberlain GR, Tulumello DV, Kelley SO (2013) Targeted delivery of doxorubicin to mitochondria. ACS Chem Biol 8(7):13891395. https://doi.org/10.1021/cb400095v

Chamoto K, Chowdhury PS, Kumar A, Sonomura K, Matsuda F, Fagarasan S, Honjo T (2017) Mitochondrial activation chemicals synergize with surface receptor PD-1 blockade for T cell-dependent antitumor activity. Proc Natl Acad Sci USA 114(5):E761-E770. https://doi.org/10.1073/pnas.1620433114

Chan DC (2006) Mitochondria: dynamic organelles in disease, aging, and development. Cell 125(7):1241-1252. https://doi. org/10.1016/j.cell.2006.06.010
Chen Z, Zhang L, Song Y, He J, Wu L, Zhao C, Xiao Y, Li W, Cai B, Cheng H, Li W (2015) Hierarchical targeted hepatocyte mitochondrial multifunctional chitosan nanoparticles for anticancer drug delivery. Biomaterials 52:240-250. https://doi. org/10.1016/j.biomaterials.2015.02.001

Chen W-H, Luo G-F, Qiu W-X, Lei Q, Liu L-H, Zheng D-W, Hong S, Cheng S-X, Zhang X-Z (2016) Tumor-triggered drug release with tumor-targeted accumulation and elevated drug retention to overcome multidrug resistance. Chem Mater 28(18):6742-6752

Chen Q, Du Y, Zhang K, Liang Z, Li J, Yu H, Ren R, Feng J, Jin Z, Li F, Sun J, Zhou M, He Q, Sun X, Zhang H, Tian M, Ling D (2018) Tau-targeted multifunctional nanocomposite for combinational therapy of Alzheimer's disease. ACS Nano 12(2):1321-1338. https://doi.org/10.1021/acsnano.7b07625

Chen C, Ni X, Jia S, Liang Y, Wu X, Kong D, Ding D (2019) Massively evoking immunogenic cell death by focused mitochondrial oxidative stress using an AIE luminogen with a twisted molecular structure. Adv Mater 31(52):1904914. https://doi. org/10.1002/adma.201904914

Cheng D-B, Zhang X-H, Gao Y-J, Ji L, Hou D, Wang Z, Xu W, Qiao Z-Y, Wang H (2019) Endogenous reactive oxygen speciestriggered morphology transformation for enhanced cooperative interaction with mitochondria. J Am Chem Soc 141(18):72357239. https://doi.org/10.1021/jacs.8b07727

Cho DY, Cho H, Kwon K, Yu M, Lee E, Huh KM, Lee DH, Kang HC (2015) Triphenylphosphonium-conjugated poly $(\varepsilon-$ caprolactone)-based self-assembled nanostructures as nanosized drugs and drug delivery carriers for mitochondria-targeting synergistic anticancer drug delivery. Adv Funct Mater 25(34):5479-5491. https://doi.org/10.1002/adfm.201501422

Choi J, Choi K, Benveniste EN, Hong Y-S, Lee J-H, Kim J, Park K (2005) Bcl-2 promotes invasion and lung metastasis by inducing matrix metalloproteinase-2. Can Res 65(13):5554-5560

Dai F, Li Q, Wang Y, Ge C, Feng C, Xie S, He H, Xu X, Wang C (2017) Design, synthesis, and biological evaluation of mitochondria-targeted flavone-naphthalimide-polyamine conjugates with antimetastatic activity. J Med Chem 60(5):20712083. https://doi.org/10.1021/acs.jmedchem.6b01846

Dare AJ, Bolton EA, Pettigrew GJ, Bradley JA, Saeb-Parsy K, Murphy MP (2015) Protection against renal ischemia-reperfusion injury in vivo by the mitochondria targeted antioxidant MitoQ. Redox Biol 5:163-168. https://doi.org/10.1016/j.redox 2015.04.008

Delgoffe GM, Powell JD (2015) Feeding an army: the metabolism of $\mathrm{T}$ cells in activation, anergy, and exhaustion. Mol Immunol 68(2):492-496

Dong L-F, Low P, Dyason JC, Wang X-F, Prochazka L, Witting PK, Freeman R, Swettenham E, Valis K, Liu J (2008) $\alpha$-Tocopheryl succinate induces apoptosis by targeting ubiquinone-binding sites in mitochondrial respiratory complex II. Oncogene 27(31):4324-4335

Dunn GP, Bruce AT, Ikeda H, Old LJ, Schreiber RD (2002) Cancer immunoediting: from immunosurveillance to tumor escape. Nat Immunol 3(11):991-998

Fiore C, Salvi M, Palermo M, Sinigaglia G, Armanini D, Toninello A (2004) On the mechanism of mitochondrial permeability transition induction by glycyrrhetinic acid. Biochim Biophys Acta (BBA) 1658(3):195-201. https://doi.org/10.1016/j.bbabi o.2004.05.012

Fitzgerald JB, Schoeberl B, Nielsen UB, Sorger PK (2006) Systems biology and combination therapy in the quest for clinical efficacy. Nat Chem Biol 2(9):458-466

Flewelling RF, Hubbell WL (1986) Hydrophobic ion interactions with membranes. Thermodynamic analysis of tetraphenylphosphonium binding to vesicles. Biophys J 49(2):531-540 
Fonseca SB, Pereira MP, Mourtada R, Gronda M, Horton KL, Hurren R, Minden MD, Schimmer AD, Kelley SO (2011) Rerouting chlorambucil to mitochondria combats drug deactivation and resistance in cancer cells. Chem Biol 18(4):445-453. https:// doi.org/10.1016/j.chembiol.2011.02.010

Frankel AD, Pabo CO (1988) Cellular uptake of the tat protein from human immunodeficiency virus. Cell 55(6):1189-1193

Friedl P, Wolf K (2003) Tumour-cell invasion and migration: diversity and escape mechanisms. Nat Rev Cancer 3(5):362-374. https:// doi.org/10.1038/nrc1075

Fulda S, Galluzzi L, Kroemer G (2010) Targeting mitochondria for cancer therapy. Nat Rev Drug Discov 9(6):447-464. https://doi. org/10.1038/nrd3137

Del Gaizo V, Mark Payne R (2003) A novel TAT-mitochondrial signal sequence fusion protein is processed, stays in mitochondria, and crosses the placenta. Mol Ther 7(6):720-730. https://doi. org/10.1016/s1525-0016(03)00130-8

Garg AD, Agostinis P (2014) ER stress, autophagy and immunogenic cell death in photodynamic therapy-induced anti-cancer immune responses. Photochem Photobiol Sci 13(3):474-487. https://doi. org/10.1039/c3pp50333j

Ghosh D, Nandi S, Bhattacharjee S (2018) Combination therapy to checkmate glioblastoma: clinical challenges and advances. Clin Transl Med 7(1):33

Gottesman MM, Fojo T, Bates SE (2002) Multidrug resistance in cancer: role of ATP-dependent transporters. Nat Rev Cancer 2(1):48-58

Ha H, Lee HB (2001) Oxidative stress in diabetic nephropathy: basic and clinical information. Curr Diab Rep 1(3):282-287

Hall AM, Schuh CD (2016) Mitochondria as therapeutic targets in acute kidney injury. Curr Opin Nephrol Hypertens 25(4):355362. https://doi.org/10.1097/mnh.0000000000000228

Hallan S, Sharma K (2016) The role of mitochondria in diabetic kidney disease. Curr Diab Rep. https://doi.org/10.1007/s1189 2-016-0748-0

Hamanishi J, Mandai M, Matsumura N, Abiko K, Baba T, Konishi I (2016) PD-1/PD-L1 blockade in cancer treatment: perspectives and issues. Int J Clin Oncol 21(3):462-473

Han M, Vakili MR, Soleymani Abyaneh H, Molavi O, Lai R, Lavasanifar A (2014) Mitochondrial delivery of doxorubicin via triphenylphosphine modification for overcoming drug resistance in MDA-MB-435/DOX cells. Mol Pharm 11(8):2640-2649. https ://doi.org/10.1021/mp500038g

Holohan C, Van Schaeybroeck S, Longley DB, Johnston PG (2013) Cancer drug resistance: an evolving paradigm. Nat Rev Cancer 13(10):714-726

Horton KL, Stewart KM, Fonseca SB, Guo Q, Kelley SO (2008) Mitochondria-penetrating peptides. Chem Biol 15(4):375-382. https ://doi.org/10.1016/j.chembiol.2008.03.015

Huo D, Zhu J, Chen G, Chen Q, Zhang C, Luo X, Jiang W, Jiang X, $\mathrm{Gu}$ Z, Hu Y (2019) Eradication of unresectable liver metastasis through induction of tumour specific energy depletion. Nat Commun 10(1):3051. https://doi.org/10.1038/s41467-019-11082-3

Ishikawa K, Takenaga K, Akimoto M, Koshikawa N, Yamaguchi A, Imanishi H, Nakada K, Honma Y, Hayashi J-I (2008) ROS-generating mitochondrial DNA mutations can regulate tumor cell metastasis. Science 320(5876):661-664

Jiang L, Li L, He X, Yi Q, He B, Cao J, Pan W, Gu Z (2015a) Overcoming drug-resistant lung cancer by paclitaxel loaded dual-functional liposomes with mitochondria targeting and $\mathrm{pH}$-response. Biomaterials 52:126-139. https://doi.org/10.1016/j.biomateria 1s.2015.02.004

Jiang WG, Sanders AJ, Katoh M, Ungefroren H, Gieseler F, Prince M, Thompson SK, Zollo M, Spano D, Dhawan P, Sliva D, Subbarayan PR, Sarkar M, Honoki K, Fujii H, Georgakilas AG, Amedei A, Niccolai E, Amin A, Ashraf SS, Ye L, Helferich
WG, Yang X, Boosani CS, Guha G, Ciriolo MR, Aquilano K, Chen S, Azmi AS, Keith WN, Bilsland A, Bhakta D, Halicka D, Nowsheen S, Pantano F, Santini D (2015b) Tissue invasion and metastasis: molecular, biological and clinical perspectives. Semin Cancer Biol 35:S244-S275. https://doi.org/10.1016/j. semcancer.2015.03.008

Jiang Y, Li Y, Zhu B (2015c) T-cell exhaustion in the tumor microenvironment. Cell Death Dis 6(6):e1792

Jones SW, Christison R, Bundell K, Voyce CJ, Brockbank SM, Newham P, Lindsay MA (2005) Characterisation of cell-penetrating peptide-mediated peptide delivery. Br J Pharmacol 145(8):1093-1102. https://doi.org/10.1038/sj.bjp.0706279

Kamarajugadda S, Stemboroski L, Cai Q, Simpson NE, Nayak S, Tan M, Lu J (2012) Glucose oxidation modulates anoikis and tumor metastasis. Mol Cell Biol 32(10):1893-1907. https://doi. org/10.1128/mcb.06248-11

Kezic A, Spasojevic I, Lezaic V, Bajcetic M (2016) Mitochondriatargeted antioxidants: future perspectives in kidney ischemia reperfusion injury. Oxid Med Cell Longev 2016:1-12. https:// doi.org/10.1155/2016/2950503

Klimpel A, Neundorf I (2018) Bifunctional peptide hybrids targeting the matrix of mitochondria. J Control Release 291:147-156. https://doi.org/10.1016/j.jconrel.2018.10.029

Kroemer G, Galluzzi L, Brenner C (2007) Mitochondrial membrane permeabilization in cell death. Physiol Rev 87(1):99-163. https ://doi.org/10.1152/physrev.00013.2006

Krysko DV, Garg AD, Kaczmarek A, Krysko O, Agostinis P, Vandenabeele P (2012) Immunogenic cell death and DAMPs in cancer therapy. Nat Rev Cancer 12(12):860-875. https://doi. org/10.1038/nrc3380

Kulawiec M, Owens KM, Singh KK (2014) Cancer cell mitochondria confer apoptosis resistance and promote metastasis. Cancer Biol Ther 8(14):1378-1385. https://doi.org/10.4161/cbt.8.14.8751

Kwon HJ, Cha M-Y, Kim D, Kim DK, Soh M, Shin K, Hyeon T, MookJung I (2016) Mitochondria-targeting ceria nanoparticles as antioxidants for Alzheimer's disease. ACS Nano 10(2):2860-2870. https://doi.org/10.1021/acsnano.5b08045

LeBleu VS, O'Connell JT, Gonzalez Herrera KN, Wikman H, Pantel K, Haigis Marcia C, de Carvalho FM, Damascena A, Domingos Chinen LT, Rocha RM, Asara JM, Kalluri R (2014) PGC- $1 \alpha$ mediates mitochondrial biogenesis and oxidative phosphorylation in cancer cells to promote metastasis. Nat Cell Biol 16(10):992-1003. https://doi.org/10.1038/ncb3039

Lee CS, Kim YJ, Lee MS, Han ES, Lee SJ (2008) 18ß-Glycyrrhetinic acid induces apoptotic cell death in SiHa cells and exhibits a synergistic effect against antibiotic anti-cancer drug toxicity. Life Sci 83(13-14):481-489. https://doi.org/10.1016/j.lfs.2008.07.014

Li L, Sun W, Li L, Liu Y, Wu L, Wang F, Zhou Z, Zhang Z, Huang Y (2017) A pH-responsive sequential-disassembly nanohybrid for mitochondrial targeting. Nanoscale 9(1):314-325. https://doi. org/10.1039/c6nr07004c

Lin R, Zhang P, Cheetham AG, Walston J, Abadir P, Cui H (2015) Dual peptide conjugation strategy for improved cellular uptake and mitochondria targeting. Bioconjug Chem 26(1):71-77. https ://doi.org/10.1021/bc500408p

Lin A, Truong B, Patel S, Kaushik N, Choi EH, Fridman G, Fridman A, Miller V (2017) Nanosecond-pulsed DBD plasma-generated reactive oxygen species trigger immunogenic cell death in A549 lung carcinoma cells through intracellular oxidative stress. Int J Mol Sci 18(5):966

Liu W, Beck BH, Vaidya KS, Nash KT, Feeley KP, Ballinger SW, Pounds KM, Denning WL, Diers AR, Landar A, Dhar A, Iwakuma T, Welch DR (2013) Metastasis suppressor KISS1 seems to reverse the warburg effect by enhancing mitochondrial biogenesis. Can Res 74(3):954-963. https://doi.org/10.1158/0008-5472. can-13-1183 
Liu Y, Li Q, Xiong X, Huang Y, Zhou Z (2018) Mitochondria-targeting and cell-penetrating peptides-co-modified HPMA copolymers for enhancing therapeutic efficacy of $\alpha$-tocopheryl succinate. J Mater Chem B 6(46):7674-7683. https://doi.org/10.1039/c8tb02621a

Liu Y, Zhou Z, Lin X, Xiong X, Zhou R, Zhou M, Huang Y (2019) Enhanced reactive oxygen species generation by mitochondria targeting of anticancer drug to overcome tumor multidrug resistance. Biomacromol 20(10):3755-3766. https://doi.org/10.1021/ acs.biomac.9b00800

Llopis J, McCaffery JM, Miyawaki A, Farquhar MG, Tsien RY (1998) Measurement of cytosolic, mitochondrial, and Golgi $\mathrm{pH}$ in single living cells with green fluorescent proteins. Proc Natl Acad Sci 95(12):6803-6808

Lowell BB, Shulman GI (2005) Mitochondrial dysfunction and type 2 diabetes. Science 307(5708):384-387

Lu J, Tan M, Cai Q (2015) The Warburg effect in tumor progression: mitochondrial oxidative metabolism as an anti-metastasis mechanism. Cancer Lett 356(2):156-164. https://doi. org/10.1016/j.canlet.2014.04.001

Lu P, Bruno BJ, Rabenau M, Lim CS (2016) Delivery of drugs and macromolecules to the mitochondria for cancer therapy. J Control Release 240:38-51. https://doi.org/10.1016/j.jconr el.2015.10.023

Luo GF, Chen WH, Liu Y, Lei Q, Zhuo RX, Zhang XZ (2014) Multifunctional enveloped mesoporous silica nanoparticles for subcellular co-delivery of drug and therapeutic peptide. Sci Rep 4:6064. https://doi.org/10.1038/srep06064

Ma P, Chen J, Bi X, Li Z, Gao X, Li H, Zhu H, Huang Y, Qi J, Zhang Y (2018) Overcoming multidrug resistance through the GLUT1-mediated and enzyme-triggered mitochondrial targeting conjugate with redox-sensitive paclitaxel release. ACS Appl Mater Interfaces 10(15):12351-12363. https://doi. org/10.1021/acsami.7b18437

Maiti KK, Lee WS, Takeuchi T, Watkins C, Fretz M, Kim D-C, Futaki S, Jones A, Kim K-T, Chung S-K (2007) Guanidinecontaining molecular transporters: sorbitol-based transporters show high intracellular selectivity toward mitochondria. Angew Chem Int Ed 46(31):5880-5884. https://doi. org/10.1002/anie.200701346

Malhi SS, Budhiraja A, Arora S, Chaudhari KR, Nepali K, Kumar R, Sohi H, Murthy RS (2012) Intracellular delivery of redox cyclerdoxorubicin to the mitochondria of cancer cell by folate receptor targeted mitocancerotropic liposomes. Int J Pharm 432(1-2):6374. https://doi.org/10.1016/j.ijpharm.2012.04.030

Marrache S, Tundup S, Harn DA, Dhar S (2013) Ex vivo programming of dendritic cells by mitochondria-targeted nanoparticles to produce interferon-gamma for cancer immunotherapy. ACS Nano 7(8):7392-7402

Matsuyama S, Llopis J, Deveraux QL, Tsien RY, Reed JC (2000) Changes in intramitochondrial and cytosolic $\mathrm{pH}$ : early events that modulate caspase activation during apoptosis. Nat Cell Biol 2(6):318-325

Meng X, Huang Z, Teng F, Xing L, Yu J (2015) Predictive biomarkers in PD-1/PD-L1 checkpoint blockade immunotherapy. Cancer Treat Rev 41(10):868-876

Menk AV, Scharping NE, Rivadeneira DB, Calderon MJ, Watson MJ, Dunstane D, Watkins SC, Delgoffe GM (2018) 4-1BB costimulation induces $\mathrm{T}$ cell mitochondrial function and biogenesis enabling cancer immunotherapeutic responses. J Exp Med 215(4):1091-1100. https://doi.org/10.1084/jem.20171068

Millard M, Gallagher JD, Olenyuk BZ, Neamati N (2013) A selective mitochondrial-targeted chlorambucil with remarkable cytotoxicity in breast and pancreatic cancers. J Med Chem 56(22):9170-9179

Mironov SL, Ivannikov MV, Johansson M (2005) [Ca2+] i signaling between mitochondria and endoplasmic reticulum in neurons is regulated by microtubules from mitochondrial permeability transition pore to $\mathrm{Ca} 2+$-induced $\mathrm{Ca} 2+$ release. J Biol Chem 280(1):715-721

Modica-Napolitano JS, Aprille JR (2001) Delocalized lipophilic cations selectively target the mitochondria of carcinoma cells. Adv Drug Deliv Rev 49(1-2):63-70

Moreno BH, Ribas A (2015) Anti-programmed cell death protein-1/ligand-1 therapy in different cancers. Br J Cancer 112(9):1421-1427

Ono A, Miyauchi S, Demura M, Asakura T, Kamo N (1994) Activation energy for permeation of phosphonium cations through phospholipid bilayer membrane. Biochemistry 33(14):4312-4318

Patel NR, Pattni BS, Abouzeid AH, Torchilin VP (2013) Nanopreparations to overcome multidrug resistance in cancer. Adv Drug Deliv Rev 65(13-14):1748-1762. https://doi.org/10.1016/j. addr.2013.08.004

Peiris-Pages M, Martinez-Outschoorn UE, Sotgia F, Lisanti MP (2015) Metastasis and oxidative stress: are antioxidants a metabolic driver of progression? Cell Metab 22(6):956-958. https://doi. org/10.1016/j.cmet.2015.11.008

Piskounova E, Agathocleous M, Murphy MM, Hu Z, Huddlestun SE, Zhao Z, Leitch AM, Johnson TM, DeBerardinis RJ, Morrison SJ (2015) Oxidative stress inhibits distant metastasis by human melanoma cells. Nature 527(7577):186-191. https://doi.org/10.1038/ nature 15726

Rogalska A, Koceva-Chyla A, Jozwiak Z (2008) Aclarubicin-induced ROS generation and collapse of mitochondrial membrane potential in human cancer cell lines. Chem Biol Interact 176(1):58-70. https://doi.org/10.1016/j.cbi.2008.07.002

Rugolo M, Lenaz G (1987) Monitoring of the mitochondrial and plasma membrane potentials in human fibroblasts by tetraphenylphosphonium ion distribution. J Bioenerg Biomembr 19(6):705-718

Saar K, Lindgren M, Hansen M, Eiriksdottir E, Jiang Y, RosenthalAizman K, Sassian M, Langel U (2005) Cell-penetrating peptides: a comparative membrane toxicity study. Anal Biochem 345(1):55-65. https://doi.org/10.1016/j.ab.2005.07.033

Sanyal AJ, Campbell-Sargent C, Mirshahi F, Rizzo WB, Contos MJ, Sterling RK, Luketic VA, Shiffman ML, Clore JN (2001) Nonalcoholic steatohepatitis: association of insulin resistance and mitochondrial abnormalities. Gastroenterology 120(5):11831192. https://doi.org/10.1053/gast.2001.23256

Saraswathy M, Gong S (2013) Different strategies to overcome multidrug resistance in cancer. Biotechnol Adv 31(8):1397-1407. https ://doi.org/10.1016/j.biotechadv.2013.06.004

Sato Y, Nakamura T, Yamada Y, Harashima H (2016) Development of a multifunctional envelope-type nano device and its application to nanomedicine. J Control Release 244:194-204

Schapira AHV (2006) Mitochondrial disease. The Lancet 368(9529):70-82. https://doi.org/10.1016/s0140-6736(06)68970 $-8$

Scharping NE, Menk AV, Moreci RS, Whetstone RD, Dadey RE, Watkins SC, Ferris RL, Delgoffe GM (2016) The tumor microenvironment represses $\mathrm{T}$ cell mitochondrial biogenesis to drive intratumoral $\mathrm{T}$ cell metabolic insufficiency and dysfunction. Immunity 45(2):374-388. https://doi.org/10.1016/j.immun i.2016.07.009

Sharma G, Kar S, Palit S, Das PK (2012) 18ß-glycyrrhetinic acid induces apoptosis through modulation of Akt/FOXO3a/Bim pathway in human breast cancer MCF-7 cells. J Cell Physiol 227(5):1923-1931. https://doi.org/10.1002/jcp.22920

Shibata S (2000) A drug over the millennia: pharmacognosy, chemistry, and pharmacology of licorice. Yakugaku Zasshi 120(10):849-862 
Shokolenko IN, Alexeyev MF, LeDoux SP, Wilson GL (2005) TATmediated protein transduction and targeted delivery of fusion proteins into mitochondria of breast cancer cells. DNA Repair 4(4):511-518. https://doi.org/10.1016/j.dnarep.2004.11.009

Sibrian-Vazquez M, Nesterova IV, Jensen TJ, Vicente MGH (2008) Mitochondria targeting by guanidine-and biguanidine-porphyrin photosensitizers. Bioconjug Chem 19(3):705-713

Smith RA, Porteous CM, Coulter CV, Murphy MP (1999) Selective targeting of an antioxidant to mitochondria. Eur J Biochem 263(3):709-716

Smith RA, Porteous CM, Gane AM, Murphy MP (2003) Delivery of bioactive molecules to mitochondria in vivo. Proc Natl Acad Sci USA 100(9):5407-5412. https://doi.org/10.1073/ pnas.0931245100

Song X-D, Kong X, He S-F, Chen J-X, Sun J, Chen B-B, Zhao J-W, Mao Z-W (2017) Cyclometalated iridium (III)-guanidinium complexes as mitochondria-targeted anticancer agents. Eur J Med Chem 138:246-254

Sotgia F, Whitaker-Menezes D, Martinez-Outschoorn UE, Flomenberg N, Birbe RC, Witkiewicz AK, Howell A, Philp NJ, Pestell RG, Lisanti MP (2012) Mitochondrial metabolism in cancer metastasis: visualizing tumor cell mitochondria and the "reverse Warburg effect" in positive lymph node tissue. Cell Cycle 11(7):1445-1454. https://doi.org/10.4161/cc.19841

Souris JS, Lee C-H, Cheng S-H, Chen C-T, Yang C-S, Ja-an AH, Mou C-Y, Lo L-W (2010) Surface charge-mediated rapid hepatobiliary excretion of mesoporous silica nanoparticles. Biomaterials 31(21):5564-5574

Steeg PS (2006) Tumor metastasis: mechanistic insights and clinical challenges. Nat Med 12(8):895-904. https://doi.org/10.1038/ nm1469

Stockwin LH, Yu SX, Borgel S, Hancock C, Wolfe TL, Phillips LR, Hollingshead MG, Newton DL (2010) Sodium dichloroacetate selectively targets cells with defects in the mitochondrial ETC. Int J Cancer 127(11):2510-2519

Sun C, Wang H, Mao S, Liu J, Li S, Wang J (2015a) Reactive oxygen species involved in CT26 immunogenic cell death induced by Clostridium difficile toxin B. Immunol Lett 164(2):65-71. https://doi.org/10.1016/j.imlet.2015.02.007

Sun W, Li L, Yang Q, Shan W, Zhang Z, Huang Y (2015b) G3-C12 peptide reverses Galectin-3 from foe to friend for active targeting cancer treatment. Mol Pharm 12(11):4124-4136. https:// doi.org/10.1021/acs.molpharmaceut.5b00568

Sun W, Li L, Li L-j, Yang Q-q, Zhang Z-r, Huang Y (2017) Two birds, one stone: dual targeting of the cancer cell surface and subcellular mitochondria by the galectin-3-binding peptide G3-C12. Acta Pharmacol Sin 38(6):806-822. https://doi. org/10.1038/aps.2016.137

Szakács G, Paterson JK, Ludwig JA, Booth-Genthe C, Gottesman MM (2006) Targeting multidrug resistance in cancer. Nat Rev Drug Discovery 5(3):219-234

Szendroedi J, Phielix E, Roden M (2011) The role of mitochondria in insulin resistance and type 2 diabetes mellitus. Nat Rev Endocrinol 8(2):92-103. https://doi.org/10.1038/nrendo.2011.138

Szeto HH (2006) Cell-permeable, mitochondrial-targeted, peptide antioxidants. AAPS J 8(2):E277-E283

Szeto HH (2008) Development of mitochondria-targeted aromaticcationic peptides for neurodegenerative diseases. Ann N Y Acad Sci 1147(1):112-121. https://doi.org/10.1196/annal s. 1427.013

Takenaka Y, Fukumori T, Yoshii T, Oka N, Inohara H, Kim HR, Bresalier RS, Raz A (2004) Nuclear export of phosphorylated galectin-3 regulates its antiapoptotic activity in response to chemotherapeutic drugs. Mol Cell Biol 24(10):4395-4406. https://doi. org/10.1128/mcb.24.10.4395-4406.2004
Tan Y, Zhu Y, Zhao Y, Wen L, Meng T, Liu X, Yang X, Dai S, Yuan H, Hu F (2018) Mitochondrial alkaline $\mathrm{pH}$-responsive drug release mediated by Celastrol loaded glycolipid-like micelles for cancer therapy. Biomaterials 154:169-181. https://doi.org/10.1016/j. biomaterials.2017.07.036

Tang F, Li L, Chen D (2012) Mesoporous silica nanoparticles: synthesis, biocompatibility and drug delivery. Adv Mater 24(12):15041534. https://doi.org/10.1002/adma.201104763

Tang J, Zhang L, Gao H, Liu Y, Zhang Q, Ran R, Zhang Z, He Q (2016) Co-delivery of doxorubicin and P-gp inhibitor by a reduction-sensitive liposome to overcome multidrug resistance, enhance anti-tumor efficiency and reduce toxicity. Drug Delivery 23(4):1130-1143

Tarn D, Ashley CE, Xue M, Carnes EC, Zink JI, Brinker CJ (2013) Mesoporous silica nanoparticle nanocarriers: biofunctionality and biocompatibility. Acc Chem Res 46(3):792-801

Tian B-P, Li F, Li R, Hu X, Lai T-W, Lu J, Zhao Y, Du Y, Liang Z, Zhu C, Shao W, Li W, Chen Z-H, Sun X, Chen X, Ying S, Ling D, Shen H (2019) Nanoformulated ABT-199 to effectively target Bcl-2 at mitochondrial membrane alleviates airway inflammation by inducing apoptosis. Biomaterials 192:429-439. https://doi. org/10.1016/j.biomaterials.2018.06.020

To KK (2013) MicroRNA: a prognostic biomarker and a possible druggable target for circumventing multidrug resistance in cancer chemotherapy. J Biomed Sci 20(1):99

Um H-D (2016) Bcl-2 family proteins as regulators of cancer cell invasion and metastasis: a review focusing on mitochondrial respiration and reactive oxygen species. Oncotarget 7(5):5193

Valastyan S, Weinberg RA (2011) Tumor metastasis: molecular insights and evolving paradigms. Cell 147(2):275-292. https:// doi.org/10.1016/j.cell.2011.09.024

Varbiro G, Veres B, Gallyas F Jr, Sumegi B (2001) Direct effect of Taxol on free radical formation and mitochondrial permeability transition. Free Radical Biol Med 31(4):548-558

Wallace DC (2012) Mitochondria and cancer. Nat Rev Cancer 12(10):685-698. https://doi.org/10.1038/nrc3365

Wang XX, Li YB, Yao HJ, Ju RJ, Zhang Y, Li RJ, Yu Y, Zhang L, $\mathrm{Lu}$ WL (2011) The use of mitochondrial targeting resveratrol liposomes modified with a dequalinium polyethylene glycol-distearoylphosphatidyl ethanolamine conjugate to induce apoptosis in resistant lung cancer cells. Biomaterials 32(24):5673-5687. https://doi.org/10.1016/j.biomaterials.2011.04.029

Wang Y, Zi X-Y, Su J, Zhang H-X, Zhang X-R, Zhu H-Y, Li J-X, Yin M, Yang F, Hu Y-P (2012) Cuprous oxide nanoparticles selectively induce apoptosis of tumor cells. Int J Nanomed 7:2641

Wang Y, Yang F, Zhang HX, Zi XY, Pan XH, Chen F, Luo WD, Li JX, Zhu HY, Hu YP (2013) Cuprous oxide nanoparticles inhibit the growth and metastasis of melanoma by targeting mitochondria. Cell Death Dis 4:e783. https://doi.org/10.1038/cddis.2013.314

Wang F, Sun W, Li L, Li L, Liu Y, Zhang ZR, Huang Y (2017) Chargereversible multifunctional HPMA copolymers for mitochondrial targeting. ACS Appl Mater Interfaces 9(33):27563-27574. https ://doi.org/10.1021/acsami.7b09693

Wang H, Gao Z, Liu X, Agarwal P, Zhao S, Conroy DW, Ji G, Yu J, Jaroniec CP, Liu Z, Lu X, Li X, He X (2018) Targeted production of reactive oxygen species in mitochondria to overcome cancer drug resistance. Nat Commun 9(1):562. https://doi.org/10.1038/ s41467-018-02915-8

Weber T, Dalen H, Andera L, Nègre-Salvayre A, Augé N, Sticha M, Lloret A, Terman A, Witting PK, Higuchi M (2003) Mitochondria play a central role in apoptosis induced by $\alpha$-tocopheryl succinate, an agent with antineoplastic activity: comparison with receptor-mediated pro-apoptotic signaling. Biochemistry 42(14):4277-4291

Wei Y, Rector RS, Thyfault JP, Ibdah JA (2008) Nonalcoholic fatty liver disease and mitochondrial dysfunction. World J Gastroenterol 14(2):193 
Wender PA, Mitchell DJ, Pattabiraman K, Pelkey ET, Steinman L, Rothbard JB (2000) The design, synthesis, and evaluation of molecules that enable or enhance cellular uptake: peptoid molecular transporters. Proc Natl Acad Sci 97(24):13003-13008

Wilhelm S, Tavares AJ, Dai Q, Ohta S, Audet J, Dvorak HF, Chan WCW (2016) Analysis of nanoparticle delivery to tumours. Nat Rev Mater. https://doi.org/10.1038/natrevmats.2016.14

Wisnovsky SP, Wilson JJ, Radford RJ, Pereira MP, Chan MR, Laposa RR, Lippard SJ, Kelley SO (2013) Targeting mitochondrial DNA with a platinum-based anticancer agent. Chem Biol 20(11):13231328. https://doi.org/10.1016/j.chembiol.2013.08.010

Wong DYQ (2018) Induction of immunogenic cell death by chemotherapeutic platinum complexes. In: Rethinking platinum anticancer drug design: towards targeted and immuno-chemotherapeutic approaches. Springer, pp 131-145

Wu H, Li F, Shao W, Gao J, Ling D (2019) Promoting angiogenesis in oxidative diabetic wound microenvironment using a nanozymereinforced self-protecting hydrogel. ACS Central Sci 5(3):477485. https://doi.org/10.1021/acscentsci.8b00850

Xiao K, Li Y, Luo J, Lee JS, Xiao W, Gonik AM, Agarwal RG, Lam KS (2011) The effect of surface charge on in vivo biodistribution of PEG-oligocholic acid based micellar nanoparticles. Biomaterials 32(13):3435-3446

Yamada Y, Harashima H (2008) Mitochondrial drug delivery systems for macromolecule and their therapeutic application to mitochondrial diseases. Adv Drug Deliv Rev 60(13-14):1439-1462. https ://doi.org/10.1016/j.addr.2008.04.016

Yamada Y, Furukawa R, Yasuzaki Y, Harashima H (2011) Dual function MITO-Porter, a nano carrier integrating both efficient cytoplasmic delivery and mitochondrial macromolecule delivery. Mol Ther 19(8):1449-1456. https://doi.org/10.1038/mt.2011.99

Yamada Y, Nakamura K, Abe J, Hyodo M, Haga S, Ozaki M, Harashima H (2015) Mitochondrial delivery of Coenzyme Q10 via systemic administration using a MITO-Porter prevents ischemia/ reperfusion injury in the mouse liver. J Control Release 213:8695. https://doi.org/10.1016/j.jconrel.2015.06.037

Yang JC, Myung SC, Kim W, Lee CS (2012a) 18ß-Glycyrrhetinic acid potentiates Hsp90 inhibition-induced apoptosis in human epithelial ovarian carcinoma cells via activation of death receptor and mitochondrial pathway. Mol Cell Biochem 370(1-2):209-219. https://doi.org/10.1007/s11010-012-1412-x

Yang Y, Zhou Z, He S, Fan T, Jin Y, Zhu X, Chen C, Zhang Z-r, Huang Y (2012b) Treatment of prostate carcinoma with (Galectin3)-targeted HPMA copolymer-(G3-C12)-5-Fluorouracil conjugates. Biomaterials 33(7):2260-2271. https://doi.org/10.1016/j. biomaterials.2011.12.007

Yang Y, Li L, Zhou Z, Yang Q, Liu C, Huang Y (2014) Targeting prostate carcinoma by G3-C12 peptide conjugated N-(2-hydroxypropyl)methacrylamide copolymers. Mol Pharm 11(10):3251-3260. https://doi.org/10.1021/mp500083u

Yang J, Cao Q, Zhang H, Hao L, Zhou D, Gan Z, Li Z, Tong YX, Ji LN, Mao ZW (2018) Targeted reversal and phosphorescence lifetime imaging of cancer cell metabolism via a theranostic rhenium(I)-DCA conjugate. Biomaterials 176:94-105. https:// doi.org/10.1016/j.biomaterials.2018.05.040

Yang Q, Peng J, Shi K, Xiao Y, Liu Q, Han R, Wei X, Qian Z (2019) Rationally designed peptide-conjugated gold/platinum nanosystem with active tumor-targeting for enhancing tumor photothermal-immunotherapy. J Control Release 308:29-43. https://doi. org/10.1016/j.jconrel.2019.06.031

Yu F, Finley RL, Raz A, Kim H-RC (2002) Galectin-3 translocates to the perinuclear membranes and inhibits cytochromec release from the mitochondria. J Biol Chem 277(18):15819-15827. https ://doi.org/10.1074/jbc.M200154200

Yu Y, Wang ZH, Zhang L, Yao HJ, Zhang Y, Li RJ, Ju RJ, Wang XX, Zhou J, Li N, Lu WL (2012) Mitochondrial targeting topotecan-loaded liposomes for treating drug-resistant breast cancer and inhibiting invasive metastases of melanoma. Biomaterials 33(6):1808-1820. https://doi.org/10.1016/j.biomateria 1s.2011.10.085

Yu W, He X, Yang Z, Yang X, Xiao W, Liu R, Xie R, Qin L, Gao H (2019) Sequentially responsive biomimetic nanoparticles with optimal size in combination with checkpoint blockade for cascade synergetic treatment of breast cancer and lung metastasis. Biomaterials 217:119309. https://doi.org/10.1016/j.biomateria 1s.2019.119309

Yue C, Yang Y, Zhang C, Alfranca G, Cheng S, Ma L, Liu Y, Zhi X, Ni J, Jiang W, Song J, de la Fuente JM, Cui D (2016) ROSresponsive mitochondria-targeting blended nanoparticles: chemo- and photodynamic synergistic therapy for lung cancer with on-demand drug release upon irradiation with a single light source. Theranostics 6(13):2352-2366. https://doi.org/10.7150/ thno. 15433

Zhang C, Wang W, Liu T, Wu Y, Guo H, Wang P, Tian Q, Wang Y, Yuan Z (2012) Doxorubicin-loaded glycyrrhetinic acid-modified alginate nanoparticles for liver tumor chemotherapy. Biomaterials 33(7):2187-2196. https://doi.org/10.1016/j.biomateria 1s.2011.11.045

Zhang S-L, Hu X, Zhang W, Yao H, Tam KY (2015) Development of pyruvate dehydrogenase kinase inhibitors in medicinal chemistry with particular emphasis as anticancer agents. Drug Discovery Today 20(9):1112-1119

Zhang C, Liu Z, Zheng Y, Geng Y, Han C, Shi Y, Sun H, Zhang C, Chen Y, Zhang L, Guo Q, Yang L, Zhou X, Kong L (2018) glycyrrhetinic acid functionalized graphene oxide for mitochondria targeting and cancer treatment in vivo. Small. https://doi. org/10.1002/smll.201703306

Zhang W, Hu X, Shen Q, Xing D (2019) Mitochondria-specific drug release and reactive oxygen species burst induced by polyprodrug nanoreactors can enhance chemotherapy. Nat Commun 10(1):1-14

Zhao K, Luo G, Zhao G-M, Schiller PW, Szeto HH (2003) Transcellular transport of a highly polar $3+$ net charge opioid tetrapeptide. J Pharmacol Exp Ther 304(1):425-432. https://doi.org/10.1124/ jpet.102.040147

Zhao K, Zhao G-M, Wu D, Soong Y, Birk AV, Schiller PW, Szeto HH (2004) Cell-permeable peptide antioxidants targeted to inner mitochondrial membrane inhibit mitochondrial swelling, oxidative cell death, and reperfusion injury. J Biol Chem 279(33):34682-34690. https://doi.org/10.1074/jbc.M402999200

Zhou J, Zhao W-Y, Ma X, Ju R-J, Li X-Y, Li N, Sun M-G, Shi J-F, Zhang C-X, Lu W-L (2013) The anticancer efficacy of paclitaxel liposomes modified with mitochondrial targeting conjugate in resistant lung cancer. Biomaterials 34(14):3626-3638. https:// doi.org/10.1016/j.biomaterials.2013.01.078

Zhou M, Li L, Li L, Lin X, Wang F, Li Q, Huang Y (2019) Overcoming chemotherapy resistance via simultaneous drug-efflux circumvention and mitochondrial targeting. Acta Pharm Sin B 9(3):615-625. https://doi.org/10.1016/j.apsb.2018.11.005

Zielonka J, Joseph J, Sikora A, Hardy M, Ouari O, Vasquez-Vivar J, Cheng G, Lopez M, Kalyanaraman B (2017) Mitochondriatargeted triphenylphosphonium-based compounds: syntheses, mechanisms of action, and therapeutic and diagnostic applications. Chem Rev 117(15):10043-10120. https://doi.org/10.1021/ acs.chemrev.7b00042

Zong W-X, Rabinowitz JD, White E (2016) Mitochondria and cancer. Mol Cell 61(5):667-676. https://doi.org/10.1016/j.molce 1.2016.02.011

Publisher's Note Springer Nature remains neutral with regard to jurisdictional claims in published maps and institutional affiliations. 